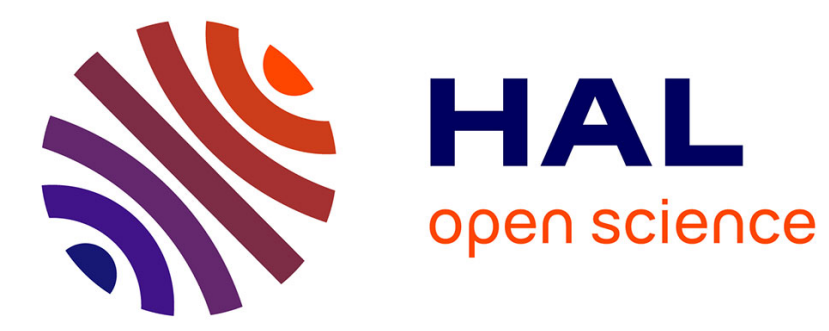

\title{
Origin and abundance of water in carbonaceous asteroids
}

\author{
Yves Marrocchi, David V Bekaert, Laurette Piani
}

\section{To cite this version:}

Yves Marrocchi, David V Bekaert, Laurette Piani. Origin and abundance of water in carbonaceous asteroids. Earth and Planetary Science Letters, 2018, 482, pp.23-32. 10.1016/j.epsl.2017.10.060 . hal-02357542

\section{HAL Id: hal-02357542 \\ https://hal.univ-lorraine.fr/hal-02357542}

Submitted on 10 Nov 2019

HAL is a multi-disciplinary open access archive for the deposit and dissemination of scientific research documents, whether they are published or not. The documents may come from teaching and research institutions in France or abroad, or from public or private research centers.
L'archive ouverte pluridisciplinaire HAL, est destinée au dépôt et à la diffusion de documents scientifiques de niveau recherche, publiés ou non, émanant des établissements d'enseignement et de recherche français ou étrangers, des laboratoires publics ou privés. 


\title{
Origin and abundance of water in carbonaceous asteroids
}

\author{
Yves Marrocchi ${ }^{*}$, David V. Bekaert and Laurette Piani \\ CRPG, CNRS, Université de Lorraine, UMR 7358, Vandoeuvre-les-Nancy, F-54501, France \\ *Corresponding author: yvesm@crpg.cnrs-nancy.fr
}

\section{Abstract}

The origin and abundance of water accreted by carbonaceous asteroids remains underconstrained, but would provide important information on the dynamic of the protoplanetary disk. Here we report the in situ oxygen isotopic compositions of aqueously formed fayalite grains in the Kaba and Mokoia CV chondrites. CV chondrite bulk, matrix and fayalite $\mathrm{O}$-isotopic compositions define the mass-independent continuous trend $\left(\delta^{17} \mathrm{O}=0.84 \pm\right.$ $0.03 \times \delta^{18} \mathrm{O}-4.25 \pm 0.1$, which shows that the main process controlling the O-isotopic composition of the $\mathrm{CV}$ chondrite parent body is related to isotopic exchange between ${ }^{16} \mathrm{O}$-rich anhydrous silicates and ${ }^{17} \mathrm{O}$ - and ${ }^{18} \mathrm{O}$-rich fluid. Similar isotopic behaviors observed in $\mathrm{CM}$, $\mathrm{CR}$ and $\mathrm{CO}$ chondrites demonstrate the ubiquitous nature of $\mathrm{O}$-isotopic exchange as the main physical process in establishing the O-isotopic features of carbonaceous chondrites, regardless of their alteration degree. Based on these results, we developed a new approach to estimate the abundance of water accreted by carbonaceous chondrites (quantified by the water/rock ratio) with $\mathrm{CM}(0.3-0.4) \geq \mathrm{CR}(0.1-0.4) \geq \mathrm{CV}(0.1-0.2)>\mathrm{CO}(0.01-0.10)$. The low water/rock ratios and the $\mathrm{O}$-isotopic characteristics of secondary minerals in carbonaceous chondrites indicate they (i) formed in the main asteroid belt and (ii) accreted a locally derived (inner Solar System) water formed near the snowline by condensation from the gas phase. Such results imply low influx of D- and ${ }^{17} \mathrm{O}$ - and ${ }^{18} \mathrm{O}$-rich water ice grains from the outer part 
of the Solar System. The latter is likely due to the presence of a Jupiter-induced gap in the protoplanetary disk that limited the inward drift of outer Solar System material at the exception of particles with size lower than $150 \mu \mathrm{m}$ such as presolar grains. Among carbonaceous chondrites, $\mathrm{CV}$ chondrites show O-isotopic features suggesting potential contribution of ${ }^{17-18} \mathrm{O}$-rich water that may be related to their older accretion relative to other hydrated carbonaceous chondrites.

\section{Highlights}

Bulk, matrix and fayalite grains of CV chondrites define a continuous trend.

O-isotopic compositions of C-rich asteroids are established by isotopic exchange.

We estimated the abundance of water accreted by carbonaceous chondrites.

Carbonaceous asteroids formed in the asteroid belt and accreted local water.

Our results support low influx of ${ }^{17} \mathrm{O}$ - and ${ }^{18} \mathrm{O}$-rich water ice from the outer Solar System.

Keywords: carbonaceous asteroids, water, oxygen isotopes, protoplanetary disk, Jupiter. 


\section{1- Introduction}

Water played a key role in shaping the Solar System as it account for about $50 \%$ by mass of all condensable species in a gas of cosmic composition (Lodders, 2003). Water vapor controls oxygen fugacity, affecting the chemistry of sub-millimeter materials formed during the evolution of the solar protoplanetary disk. As bouncing and fragmentation limit the coagulation of dust particles, the growth processes from dust to planetesimals are not fully understood (Güttler et al., 2010). Water-ice mantling grain surfaces is believed to enhance their adhesion and promote particle coagulation processes (Gundlach and Blum, 2015). Thus, condensed water ices can locally increase the abundance of solids, favoring conditions that trigger streaming instabilities, and allowing the growth of decimeter-sized pebbles that can accrete to form planetesimals (Ros and Johansen, 2013). Water ice is thus fundamental to the evolution of the Solar System, and, alongside oxides, silicates and metal, likely represented a significant fraction of the building blocks of planets. Ice-free chondrite accretion likely took place during the evolution of the protoplanetary disk as attested by enstatite chondrites, which show really limited traces of water (Brearley, 2006; Piani et al., 2011).

Within the solar protoplanetary disk, the formation of water ice is mainly controlled by the snowline, i.e., the distance from the Sun at which temperature is low enough for water to condense (about $150-170 \mathrm{~K}$ ). The location of the snowline in the protoplanetary disk is a direct function of the stellar accretion rate and is expected to move inward as the accretion rate decreases with time (Bitsch et al., 2015). Based on astronomical observations, stellar accretion rates are estimated to have decreased on average from $10^{-8} \mathrm{M}_{\odot} / \mathrm{y}$ at $1 \mathrm{My}$ to $1-510^{-9}$ $\mathrm{M}_{\odot} / \mathrm{y}$ at $3 \mathrm{My}\left(\mathrm{M}_{\odot}=\right.$ the solar mass $\left.\sim 210^{30} \mathrm{~kg}\right)$ (Hartmann et al., 1998), inducing the snowline to drift from $3 \mathrm{AU}$ to $1 \mathrm{AU}$ (astronomical unit $\mathrm{AU}=150 \times 10^{6} \mathrm{~km}$, the distance from Earth to the Sun) (Bitsch et al., 2015). Such a snowline drift implies that water ice grains were ubiquitous in the inner Solar System, and formed abundant ice-rich planetesimals. This 
105 point is not insignificant as geochemical constraints and numerical simulations suggest that 106 inner planetesimals should have grown "dry" with only a small contribution of ice-rich 107 planetesimals originating from larger heliocentric distances (Albarède, 2009; Marty, 2012).

108 Yet, the accretion of chondrites occurred $2-4$ My after the formation of Calcium109 Aluminum-rich Inclusions (CAIs; Sugiura and Fujiya, 2014), when the snowline should have 110 been closer to the Sun than the inner edge of the asteroid belt (Morbidelli et al., 2016). Such a 111 conundrum, referred as the snowline problem (Oka et al., 2011), could be linked to inhibited 112 water ice condensation due to the slower drift of the snowline than that of gas in the 113 protoplanetary disk (Morbidelli et al., 2016). This would bring "dry" gas (from which water 114 had already condensed farther out in the disk) in the vicinity of the snowline (Morbidelli et al., 115 2016). However, chondrites have been affected by variable but widespread water alteration 116 processes, suggesting they accreted a significant amount of water ice (Doyle et al., 2015; 117 Garenne et al., 2014; Vacher et al., 2017). Thus, the origin and the abundance of water 118 accreted by different group of chondrites are not yet fully understood (Alexander, 2017; 119 Vacher et al., 2016). Additionally, the oxygen isotopic evolution of water during secondary 120 alteration processes has not been fully investigated, and could provide invaluable information 121 on the physico-chemical processes occurring during the geological evolution of carbonaceous asteroids (Clayton and Mayeda, 1999; 1984).

124 Mean Ocean Water $(\mathrm{SMOM})$ as $\delta^{\mathrm{x}} \mathrm{O}=\left[\left({ }^{\mathrm{x}} \mathrm{O} /{ }^{16} \mathrm{O}\right)_{\text {sample }}\left(\left({ }^{\mathrm{x}} \mathrm{O} /{ }^{16} \mathrm{O}\right)_{\mathrm{SMOW}}-1\right] \times 1000\right)$ with $\mathrm{x}$ being

$125{ }^{17} \mathrm{O}$ or ${ }^{18} \mathrm{O}$; mass-independent oxygen isotope fractionation are described by the parameter $126 \Delta^{17} \mathrm{O}=\delta^{17} \mathrm{O}-0.52 \times \delta^{18} \mathrm{O}$. Among meteorites, carbonaceous chondrites present the most 127 widespread evidences of fluid-rock interactions, in that the contain important diversity of 128 aqueously formed minerals such as phyllosilicates, carbonates and magnetite (Brearley, 129 2006). Oxygen isotopic compositions of these secondary minerals can be used to decipher the 
130 origin of water in the chondrite-forming region as outer water ices are expected to exhibit 131 significant ${ }^{17} \mathrm{O}$ and ${ }^{18} \mathrm{O}$ enrichment $\left(\Delta^{17} \mathrm{O}>>0\right)$ relative to inner Solar System values $\left(\Delta^{17} \mathrm{O} \approx\right.$

132 0) due to the self-shielding of ${ }^{16} \mathrm{O}$-rich nebular $\mathrm{CO}$ gas by UV light (Yurimoto and Kuramoto,

133 2004). In addition, oxygen isotopic compositions at both the bulk and mineral scales can be

134 used to quantify (i) the abundance of water accreted by carbonaceous parent bodies (Clayton 135 and Mayeda, 1984; Young et al., 1999) and (ii) the prevailing conditions during subsequent 136 fluid-rock (Verdier-Paoletti et al., 2017). Among secondary minerals, fayalite $\left(\mathrm{Fe}_{2} \mathrm{SiO}_{4}\right)$ is of 137 primary importance as it represents a proxy of the fluid from which it formed due to its low 138 fractionation factor $\alpha_{\text {Fa-water }}$ (Zheng, 1993) at the temperature range estimated for fayalite 139 formation (i.e., 100-300 ${ }^{\circ} \mathrm{C}$ ) (Doyle et al., 2015; Zolotov et al., 2006). In this contribution, we 140 report the oxygen isotopic compositions of fayalite in the CV chondrites Kaba and Mokoia.

141 We compute the amount of water ice accreted by combining these results with the bulk O-

142 isotopic compositions of CV chondrites (Clayton and Mayeda, 1999). We also compare the

143 O-isotopic composition at both the bulk and (secondary) mineral scales for CO, CM and CR 144 chondrites to propose a quantitative view of the origin, abundance and O-isotopic evolution of 145 water in the carbonaceous asteroids.

146

147

148

149

150

151

152

153

154 Energy Dispersive X-ray (EDX) spectral analyses were performed at Centre de Recherches

155 Pétrographiques et Géochimiques (CRPG-CNRS, Nancy, France) using a JEOL JSM-6510

156 equipped with an EDX Genesis X-ray detector, using a $3 \mathrm{nA}$ primary beam at $15 \mathrm{kV}$.

157 Quantitative compositional analyses of fayalite were made with a CAMECA SX-100 electron 
microprobe at the University of Paris VI. Electron microprobe analyses of silicates were

159 performed with a $40 \mathrm{nA}$ focused beam, $15 \mathrm{kV}$ accelerating potential, and 20 on-peak and 160 background analysis times. Detection limits in silicates were $0.02 \mathrm{wt} \%$ for $\mathrm{SiO}_{2}, \mathrm{Al}_{2} \mathrm{O}_{3}, \mathrm{CaO}$ 161 and $\mathrm{MgO}, 0.01 \mathrm{wt} \%$ for $\mathrm{Na}_{2} \mathrm{O}, \mathrm{K}_{2} \mathrm{O}$, and $\mathrm{TiO}_{2}$, and $0.04 \mathrm{wt} \%$ for $\mathrm{Cr}_{2} \mathrm{O}_{3}$ and $\mathrm{FeO}$. CNRS. ${ }^{16} \mathrm{O}^{-},{ }^{17} \mathrm{O}^{-}$, and ${ }^{18} \mathrm{O}^{-}$ions produced by a $5 \mathrm{nA} \mathrm{Cs}^{+}$primary ion beam were measured in

164 multi-collection mode with three Faraday cup (FC). To avoid interference of ${ }^{16} \mathrm{OH}^{-}$and ${ }^{17} \mathrm{O}^{-}$

165 signals at mass 17 , and to maximize the flatness of the ${ }^{16} \mathrm{O}^{-}$and ${ }^{18} \mathrm{O}^{-}$peaks, entrance and exit

166 slits were adjusted to achieve a Mass Resolving Power of $\sim 7000$ for ${ }^{17} \mathrm{O}^{-}$on the central FC 167 and 2500 on the off-axis FC. Total measurement time was $240 \mathrm{~s}(180 \mathrm{~s}$ measurement $+60 \mathrm{~s}$

168 pre-sputtering). We used four terrestrial standard materials (San Carlos olivine, magnetite,

169 diopside, and fayalite) to: (i) define the mass fractionation line (TFL) and (ii) correct the 170 matrix effects on instrumental mass fractionation for fayalite. Typical count rates obtained on

171 fayalite grains were $3 \times 10^{9}$ cps for ${ }^{16} \mathrm{O}, 1 \times 10^{6}$ cps for ${ }^{17} \mathrm{O}$, and $4.5 \times 10^{6}$ cps for ${ }^{18} \mathrm{O}$. Typical $1722 \sigma$ errors were $\sim 0.7 \%$ for $\delta^{18} \mathrm{O}, \sim 0.8 \%$ for $\delta^{17} \mathrm{O}$, and $\sim 1 \%$ for $\Delta^{17} \mathrm{O}$.

173

174

175

176

177

178

179

180

181

182

183

\section{3-Results}

Fayalite grains in Kaba and Mokoia occur in peripheral portions of type I chondrules, in fine-grained chondrule rims, and in matrix (Fig. 1). Fayalite are large, subhedral-toanhedral grains, and sometimes associated with magnetite and sulfide grains (Fig. 1A), although sulfide- and magnetite-free fayalite grains are commonly observed in the matrix (Fig. 1B). Fayalite are chemically homogeneous ( $\mathrm{Fa}_{97}$ to $\mathrm{Fa}_{100}$; Table 1) with compositions similar to those previously reported fayalite-bearing assemblages (Choi et al., 2000; Hua and Buseck, 1995; Jogo et al., 2009). Eight large (> $40 \mu \mathrm{m})$ sulfide- and magnetite-free fayalite 
184

grains were selected for isotopic analyses. Their O-isotopic compositions fall above the TFL, with $\Delta^{17} \mathrm{O}$ values ranging from 0.8 to $2.6 \%$ (Fig. 2, Table 2).

\section{4-Discussion}

\subsection{Origin, abundance and O-isotopic evolution in CV chondrites}

It is commonly accepted that bulk O-isotopic compositions of $\mathrm{CV}$ chondrites plot along the Carbonaceous Chondrite Anhydrous Mineral $(\mathrm{CCAM})$ line $\left[\delta^{17} \mathrm{O}=(0.94 \pm 0.01) \times\right.$ $\left.\delta^{18} \mathrm{O}-4.2\right]$, derived from $\mathrm{BrF}_{5}$ analyses of anhydrous minerals from CAIs in carbonaceous chondrites (Clayton et al., 1973). In detail, it rather appears that bulk and matrix O-isotopic compositions of $\mathrm{CV}$ chondrites define the trend $\delta^{17} \mathrm{O}=0.84 \times \delta^{18} \mathrm{O}-4.25\left(\mathrm{r}^{2}=0.99\right.$; Fig. 2A; (Clayton and Mayeda, 1999; Greenwood et al., 2010), which likely corresponds to secondary alteration processes. The O-isotopic compositions of fayalite grains reported here do not fall on the TFL but show $\Delta^{17} \mathrm{O}>0 \%$ (Fig. 2B). When plotted with the bulk, matrix and dark inclusions O-isotopic compositions of $\mathrm{CV}$ chondrites, the Kaba and Mokoia fayalite grains define the continuous trend $\delta^{17} \mathrm{O}=(0.83 \pm 0.02) \times \delta^{18} \mathrm{O}-(4.18 \pm 0.13)\left(2 \sigma, \mathrm{r}^{2}=0.99\right.$, and Mean Squared Weight Deviation, MSWD = 3.9; Fig. 2A). Fayalite grains reported in the CV3 chondrite A-881317 also fall on this trend (Fig. 2A) (Doyle et al., 2015). Comparison with other studies is difficult due to the large uncertainties associated with O-isotope measurements (e.g., 4.4 and $2.5 \%$ on $\delta^{18} \mathrm{O}$ and $\delta^{17} \mathrm{O}(2 \sigma)$, respectively) (Choi et al., 2000). However, recent measurements in the Kaba chondrite aligns perfectly along the line of slope 0.83 (Fig. 2A; Krot and Nagashima, 2016). The continuous trend defined by bulk, matrix and fayalite compositions does not follow a mass-dependent fractionation relationship (Fig. 2A), implying that fayalite O-isotopic compositions did not result from fluid circulation along a temperature gradient, which would produce a trend with slope 0.52 . Instead, this implies that 
213 the main process controlling the O-isotopic composition of the $\mathrm{CV}$ chondrite parent body is 214 related to isotopic equilibrium between ${ }^{16} \mathrm{O}$-rich anhydrous silicates and ${ }^{17} \mathrm{O}$ - and ${ }^{18} \mathrm{O}$-rich 215 fluid as recently reported in CM chondrites (Verdier-Paoletti et al., 2017). In such a scheme, $216{ }^{17} \mathrm{O}$ - and ${ }^{18} \mathrm{O}$-rich fayalite correspond to early precipitates from primitive fluids that did not 217 suffer significant O-isotopic exchange with ${ }^{16} \mathrm{O}$-rich anhydrous silicates (Yurimoto et al., 218 2014; Zolensky et al., 2017). Conversely, lighter isotopic compositions indicate that fayalite 219 formed only after significant alteration, as fluid O-isotopic compositions converge toward the typical ${ }^{16} \mathrm{O}$-rich values of anhydrous silicates. Both bulk and mineral phase data (Fig. 2) thus identify O-isotopic exchange between ${ }^{16} \mathrm{O}$-rich silicates and ${ }^{17} \mathrm{O}$ - and ${ }^{18} \mathrm{O}$-rich fluid as the key process controlling the O-isotopic composition of the alteration fluids from which fayalite precipitated.

Thermodynamic calculations suggest that nearly pure fayalite grains $(\mathrm{Fa}>90)$ as observed in $\mathrm{CV} 3_{\mathrm{OxB}}$ chondrites are stable at temperatures below $350^{\circ} \mathrm{C}$ (Zolotov et al., 2006), and likely down to $100-200^{\circ} \mathrm{C}$ (Doyle et al., 2015). Considering the low $\alpha_{\text {Fa-water }}$ at this temperature range (i.e., $1000 \ln \alpha_{F a-\text { water }}=-3.4 \%$ at $100^{\circ} \mathrm{C}$ and $-1.1 \%$ at $200^{\circ} \mathrm{C}$, (Zheng, 1993), fayalite O-isotopic compositions represent a direct record of the oxygen isotopic compositions of the fluid from which they precipitated. Additionally, fayalite and magnetite from chondrite A-881317 lie on a mass-dependent fractionation line with $\Delta^{17} \mathrm{O}=$ $231-0.3 \%$, consistent with equilibrium crystallization from the same fluid reservoir (Fig. 3B) 232 (Doyle et al., 2015). The $-8.4 \%$ difference between $\delta^{18} \mathrm{O}$ values of fayalite and magnetite 233 (Doyle et al., 2015) corresponds to fayalite crystallization at $\approx 150^{\circ} \mathrm{C}$ (Zheng, 1993), at which 234 temperature the fractionation factor $\alpha$ is minimal with $1000 \ln \alpha_{\mathrm{Fa}-w a t e r} \square \square \square 0.6 \square \%$. 235 Considering then that fayalite formation likely occurred in a very narrow range of 236 temperatures (i.e., $150-200^{\circ} \mathrm{C}$ ), their parent fluids are characterized by near terrestrial values 237 with $\Delta^{17} \mathrm{O}$ from -1 to $+3.5 \%$ (Fig. $2 \mathrm{~A}$ ). However, these values do not necessarily correspond 
to the initial O-isotopic composition of water accreted by $\mathrm{CV}$ chondrites as protracted fluid-

239 rock interactions likely occurred before the precipitation of the rare, nearly pure, fayalite 240 grains.

There is a lively debate on the conditions of secondary alteration processes that have 242 affected chondrites, which is basically divided into open-system (Young et al., 1999) versus 243 closed-system models (Clayton and Mayeda, 1999). Although the O-isotopic compositions of 244 secondary minerals have been used to argue for both models, petrographic observations 245 appear more consistent with closed-system alteration. For instance, there is little evidence for 246 the redistribution of soluble elements within chondrites at scale greater than $100 \mu \mathrm{m}$ (Brearley, 247 2006), thus suggesting that aqueous alteration processes are mostly isochemical. This is 248 consistent with the estimated low permeability of chondrites (Bland et al., 2009) and the lack 249 of variations in bulk chemical compositions between meteorites with different degrees of 250 aqueous alteration (Brearley, 2006). Based on these observations, we thus considered a 251 closed-system model to discuss the alteration conditions of carbonaceous asteroids. In a closed system, the difference between the final (f) oxygen isotopic composition of 253 rock $r$ and water $w$ can be described as:

$$
\Delta=\delta_{r}^{f}-\delta_{w}^{f}
$$

258 The amount of water accreted by $\mathrm{CV}$ chondrites can be estimated by the water/rock ratio 259 (Young et al., 1999) 


$$
\frac{N_{w}}{N_{r}}=\frac{\left(\delta_{r}^{f}-\delta_{r}^{0}\right)}{\delta_{w}^{0}-\left(\delta_{r}^{f}-\Delta\right)}
$$

262 where $N$ corresponds to the number of oxygen atoms in the reacting water (w) or rock (r), $\delta^{\varnothing}$ 263 their initial isotopic compositions, $\delta$ their final isotopic compositions and $\Delta$ represent the 264 difference between rock and water at equilibrium. Such a formalism does not include the final 265 isotopic composition of the water, which is generally not known. However, in the case where this parameter can be calculated, Eqn. 2 simplifies to:

$$
\frac{N_{w}}{N_{r}}=\frac{\left(\delta_{r}^{f}-\delta_{r}^{0}\right)}{\left(\delta_{w}^{0}-\delta_{w}^{f}\right)}
$$

Considering the bulk O-isotopic composition of Kaba $\left(\delta^{18} \mathrm{O}=2.18 \%\right.$, (Clayton and Mayeda, 1999) and a more ${ }^{16} \mathrm{O}$-rich bulk $\mathrm{CV}$ chondrite as a plausible $\mathrm{CV}$ protolith $\left(\delta^{18} \mathrm{O}=-4.22 \%\right.$;

272 (Clayton and Mayeda, 1999), we calculate the water/rock ratio by assuming that the lowest $273 \delta^{18} \mathrm{O}$ value of fayalite represent the final $\mathrm{O}$-isotopic composition of $\mathrm{CV}$ water, after weighting 274 by the fractionation factor at $150^{\circ} \mathrm{C}$ (i.e., $17.4-0.6=16.8 \%$; Table 2 ). Although the initial 275 composition of water accreted by CV chondrite is unknown, it must be (i) located on the trend 276 defined by both bulk CV and fayalite (Fig. 2A) and (ii) characterized by $\delta^{18} \mathrm{O}$ value higher 277 than the highest fayalie $\delta^{18} \mathrm{O}$ value. Assuming an initial water with $\delta^{18} \mathrm{O}=30 \%$ (as estimated 278 for CM chondrites; (Clayton and Mayeda, 1984) leads to an estimated water/rock ratio of 0.48 279 for Kaba; the same calculation giving a result of 0.74 for Mokoia. These values are slightly 280 lower than those estimated on the basis of mineral assemblages and thermodynamic modeling 281 (i.e., 0.8-1.1; (Zolensky et al., 1993) However, it is noted that our estimations represent 282 maximum water/rock ratios, as increasing the $\delta^{18} \mathrm{O}$ of the initial water or decreasing $\delta^{18} \mathrm{O}$ of 
283 final water lowers the water/rock ratio. For instance, an initial water with $\delta^{18} \mathrm{O}=45 \%$ gives 284 estimated water/rock ratios for Kaba and Mokoia of 0.30 and 0.22 , respectively. Considering 285 the range of water/rock ratios modeled for the formation of near pure fayalite (i.e., 0.1-0.2; 286 (Zolotov et al., 2006) provides $\delta^{18} \mathrm{O} \geq+60 \%$ (i.e., $\Delta^{17} \mathrm{O}>15 \%$ ) for the initial $\mathrm{CV}$ water, 287 suggesting a potential contribution of water ice from the outer Solar System (Sakamoto et al., 2007; Seto et al., 2008).

Kaba is considered the least altered oxidized CV chondrite with a petrographic grade of 3.1-3.4 (Bonal et al., 2006). Interestingly, Kaba fayalite grains are not in isotopic equilibrium with sulfide-associated magnetite (SAMs) poikilitically enclosed in low-Ca pyroxenes of chondrules (Fig. 3; (Marrocchi et al., 2016). Based on petrographic and isotopic characteristics, SAMs have been interpreted as magmatic minerals, resulting from the crystallization of FeS melts containing variable amounts of dissolved oxygen (Marrocchi et al., 2016; Marrocchi and Libourel, 2013). The fact that the $\Delta^{17} \mathrm{O}$ of SAMs and fayalite grains from Kaba do not overlap (Fig. 3B) confirms that chondrule SAMs could be primary mineral formed during the high-temperature chondrule-forming event (Marrocchi et al., 2016). This does not exclude the potential occurrence of low-temperature aqueously formed magnetite in $\mathrm{CV}$ chondrites, but rather suggests that both processes occurred at different settings and under 300 different physico-chemical conditions.

\subsection{Comparison of $\mathrm{CV}$ to $\mathrm{CM}, \mathrm{CR}$ and $\mathrm{CO}$ chondrites}

In a oxygen three-isotope plot, the continuous trend observed between whole rocks

\subsubsection{CM chondrites} and secondary minerals is not unique to $\mathrm{CV}$ chondrites. In $\mathrm{CM}$ chondrites, Ca-carbonates replace fayalite as aqueously formed minerals defining the trend $\delta^{17} \mathrm{O}=(0.66 \pm 0.05) \times \delta^{18} \mathrm{O}$ - 
$(4.7 \pm 1.5)$ (Verdier-Paoletti et al., 2017). This implies that isotopic equilibrium between ${ }^{16} \mathrm{O}$ -

311 rich anhydrous silicates and ${ }^{17} \mathrm{O}$ - and ${ }^{18} \mathrm{O}$-rich water controls the O-isotopic evolution of bulk

$312 \mathrm{CM}$ chondrites and their secondary alteration mineral. To the first order, isotopic equilibrium

313 dominates, with temperature gradients having a lesser effect in establishing the isotopic

314 composition of $\mathrm{CV}$ and $\mathrm{CM}$ chondrites. Consequently, the isotopic compositions of secondary

315 minerals are mainly controlled by the extent of isotopic exchange between water of initial

316 composition and anhydrous silicates (Clayton and Mayeda, 1984; Verdier-Paoletti et al., 2017). In such a scheme, ${ }^{17} \mathrm{O}$ - and ${ }^{18} \mathrm{O}$-rich secondary minerals correspond to early precipitates from primitive fluids that had not yet suffered significant O-isotopic exchange with anhydrous silicates.

In $\mathrm{CM}$ chondrites, the O-isotopic compositions of alteration water inferred from direct measurements and mass balance calculations define a continuous trend, parallel within errors to that of bulk CMs and Ca-carbonates, but with a different intercept $\left(\delta^{17} \mathrm{O}=(0.69 \pm 0.02) \times\right.$ $\delta^{18} \mathrm{O}-(2.12 \pm 0.30)$; (Verdier-Paoletti et al., 2017). This difference in intercepts is directly related to the isotopic fractionation factor, reflecting an average calculated precipitation temperature of $110^{\circ} \mathrm{C}$ for $\mathrm{CM} \mathrm{Ca-carbonates} \mathrm{(Verdier-Paoletti} \mathrm{et} \mathrm{al.,} \mathrm{2017).} \mathrm{Similarly,} \mathrm{Ca-}$ carbonates of the Murchison and Mighei CM chondrites define a trend parallel to the $\mathrm{CM}$ water line, but with an intercept in good agreement, within errors, to that reported for 9 different $\mathrm{CM}$ chondrites $\left(\delta^{17} \mathrm{O}=(0.70 \pm 0.03) \times \delta^{18} \mathrm{O}-(5.65 \pm 1.25)\right.$ (Fig. 4A: (Lindgren et al., 2017; Verdier-Paoletti et al., 2017). Such results allow calculation of the O-isotopic composition of the fluid from which a given carbonate precipitated by connecting the $\mathrm{Ca}$ 331 carbonate trend to the CM water line by a mass-dependent line (see (Verdier-Paoletti et al., 2017) for further details). Using the bulk O-isotopic composition of Murchison and Mighei

333 (i.e., 7.3 and 7.6\%, respectively; (Clayton and Mayeda, 1999) and the O-isotopic composition

334 of anhydrous $\mathrm{CM}$ silicates as plausible $\mathrm{CM}$ protolith (i.e., $\delta^{18} \mathrm{O}=-4.2 \%$; (Clayton and 
335 Mayeda, 1999), we calculate the water/rock ratio (Eqn. 3) assuming that the lowest Ca336 carbonate $\delta^{18} \mathrm{O}$ value in a given $\mathrm{CM}$ chondrite represent the final $\delta^{18} \mathrm{O}$ value of water

337 (weighted by $14.6 \%$, representing $1000 \ln \alpha_{\text {calcite-water }}$ at $110^{\circ} \mathrm{C}$ ). Murchison and Mighei thus

338 show water/rock ratios of 0.32 and 0.36 , respectively, in good agreement with previous 339 estimates for CM2 chondrites (i.e., 0.3-0.6; (Clayton and Mayeda, 1984; Zolensky et al., 340 1997)

341 With the exception of few Ca-carbonates enriched in ${ }^{17} \mathrm{O}$ - and ${ }^{18} \mathrm{O}$ relative to the main 342 carbonate trend (Vacher et al., 2016), the O-isotopic characteristics of secondary mineral in 343 CM chondrites indicate a dominant local origin of water during accretion (Alexander et al., 344 2012). Near terrestrial $\Delta^{17} \mathrm{O}$ values of the $\mathrm{CM}$ water line (-1 to $+4 \%$; Fig. 4B) confirm a 345 local water origin. Consequently, the contribution in CM chondrites of water coming from 346 large heliocentric distances is probably limited to few \%. Such contributions could have been overprinted by water inherited from the inner Solar System, as indicated by the hydrogen isotopic composition of CM chondrites (Piani et al., 2017).

Of the carbonaceous chondrites, CR chondrites are of primary importance because they exhibit low degree of aqueous alteration and thermal metamorphism (Le Guillou and Brearley, 2014). Nonetheless, they experienced significant alteration as attested by the corrosion of Fe-Ni metal beads (Morlok and Libourel, 2013) and the presence of Cacarbonates (Brearley, 2006). Interestingly, CR chondrites show similar O-isotopic

357 characteristics as $\mathrm{CV}$ and $\mathrm{CM}$ chondrites, with bulk and Ca-carbonates O-isotopic 358 compositions defining the trend with $\delta^{17} \mathrm{O}=(0.63 \pm 0.02) \times \delta^{18} \mathrm{O}-(2.22 \pm 0.26)$ (Fig. 5A; 359 (Clayton and Mayeda, 1984; Jilly, 2015; Schrader et al., 2011). This similarity attests the 
ubiquitous nature of $\mathrm{O}$-isotopic exchange as the main physical process controlling the $\mathrm{O}$ -

361 isotopic compositions of carbonaceous chondrites, whatever the extent of alteration.

Magnetite in CR chondrites is sometimes in close association with Ca-carbonates

363

364

$$
\Delta^{18} \mathrm{O}_{\mathrm{mt}-\mathrm{CC}}=\left(-2.10 \times 10^{-4} \mathrm{~T}^{-2}\right)+(0.12 \mathrm{~T})-34.46
$$

Based on data from different CR chondrites (Jilly, 2015), this calculation provides a formation temperature estimate of $15-110^{\circ} \mathrm{C}$, in good agreement with previous estimations of 50- $150^{\circ} \mathrm{C}$ (Zolensky et al., 1993). At those temperature, we compute the O-isotopic compositions of water from which carbonates and magnetite formed in the different CR chondrites (Jilly, 2015; Jilly et al., 2014). CR water thus (i) defines a trend with $\delta^{17} \mathrm{O}=(0.61$ $\pm 0.03) \times \delta^{18} \mathrm{O}+(0.42 \pm 0.15)($ Fig. $6 \mathrm{~A})$ and (ii) is characterized by $\Delta^{17} \mathrm{O} \sim 0 \%$, consistent with water originating from the inner Solar System. Interestingly, the CR water trend estimated from the O-isotopic compositions of Ca-carbonates and magnetite perfectly aligns with the estimation of the O-isotopic composition of water accreted by $\mathrm{CM}$ chondrites (Clayton and Mayeda, 1999; 1984) (Fig. 5A). This suggests that both types of chondrites could have accreted similar water, implying that the $\delta^{17} \mathrm{O}$ and $\delta^{18} \mathrm{O}$ values of initial $\mathrm{CM}$ water could be used to estimate the CR chondrite W/R ratios.

Definition of the CR water line allows calculation of the O-isotopic composition of the specific fluid from which a given CR carbonate precipitated, as their respective O-isotopic 
compositions are related by a mass-dependent relationship. This further allows estimation of

386 the water/rock ratio by assuming that (i) the lowest O-isotopic composition of bulk CR 387 chondrites represent the $\delta^{18} \mathrm{O}$ of the CR protolith (i.e., -2.29\%; Fig. 5A; (Schrader et al., 2011) and (ii) the initial CR water is similar to that accreted by $\mathrm{CM}$ chondrites (i.e., 30\%o; (Clayton and Mayeda, 1984). This leads to a maximum estimation of the CR water/rock ratio in the range 0.10 to 0.40 , lower than previous values of 0.4-1.1 (Zolensky et al., 1993).

391

\subsubsection{CO chondrites}

The case of CO chondrites is more complex than other carbonaceous chondrites. First, $\mathrm{CO}$ chondrites have experienced minimal fluid alteration; some show no evidence of alteration, whereas others exhibit alteration features at the sub-micrometer scale (Brearley, 2006). Rare secondary phases (phyllosilicates, fine-grained serpentine and saponite) are mainly located within the CO matrices (Brearley, 2006). Secondly, the bulk O-isotopic compositions of $\mathrm{CO}$ chondrite finds could have been affected by terrestrial weathering, inducing a shift toward ${ }^{17} \mathrm{O}$ - and ${ }^{18} \mathrm{O}$-rich values (Greenwood and Franchi, 2004). Finally, a recent report of the bulk O-isotopic composition of $\mathrm{CO}$ chondrite falls show they are slightly shifted toward the CCAM line (Alexander et al., 2017) relative to previous measurements (Clayton and Mayeda, 1999; Greenwood and Franchi, 2004) (Fig. S1). The reason for such a shift remains unclear but could be linked to incomplete fluorination in previous measurements (Alexander et al., 2017). However, several observations can be used to improve our understanding of $\mathrm{CO}$ chondrites. (i) Considering the data reported by (Clayton and Mayeda, 1999; Greenwood and Franchi, 2004), the bulk O-isotopic compositions of CO chondrite falls show a significant deviation from the primordial slope 1 with $\delta^{17} \mathrm{O}=(0.65 \pm 0.12) \times \delta^{18} \mathrm{O}$ $(4.19 \pm 0.27)\left(\right.$ Fig. $6 \mathrm{~A} ; \mathrm{r}^{2}=0.89, \mathrm{MSWD}=7.6$ ). (ii) This trend is similar to the one defined by $\mathrm{CM}$ chondrites (Fig. 6A). Although recent report suggest that $\mathrm{CM}$ and $\mathrm{CO}$ chondrites 
could originate from distinct parent bodies (Schrader and Davidson, 2017), they probably

413 formed in a common region within the accretion disk; the anhydrous precursors of CM2 were

414 CO3-like, but CM accreted more water (Hewins et al., 2014). (iii) Taken together, the CM

415 and $\mathrm{CO}$ falls define a trend with $\delta^{17} \mathrm{O}=(0.69 \pm 0.04) \times \delta^{18} \mathrm{O}-(4.05 \pm 0.18)\left(\right.$ Fig. $6 \mathrm{~A} ; \mathrm{r}^{2}=$

416 0.98, MSWD = 15). Although the bulk O-isotopic compositions of CO chondrites are more

417 restricted than those of $\mathrm{CM}$ chondrites (Fig. 6a), they might have recorded fluid alteration

418 processes. (iv) The absence of secondary phases that could be targeted by ion probe

419 measurements precludes the possibility of combining bulk and mineral data (as reported for

420 CV, CM and CR chondrites). However, MacAlpine Hills (MAC) 88107, a CO-like chondrite,

421 shows abundant near-pure fayalite and magnetite (Krot et al., 2000) that can be used to

422 estimate the isotopic characteristics of $\mathrm{CO}$ water. The O-isotopic compositions of fayalite

423 from MAC 88107 fall along the trend defined by the bulk $\mathrm{CM}$ and $\mathrm{CO}$ chondrites, $\delta^{17} \mathrm{O}=$

$424(0.69 \pm 0.03) \times \delta^{18} \mathrm{O}-(4.01 \pm 0.21)\left(\right.$ Fig. $6 \mathrm{~A} ; \mathrm{r}^{2}=0.98$, MSWD $\left.=15\right)$. These observations

425 suggest that the O-isotopic characteristics of $\mathrm{CO}$ chondrites were established by O-isotopic

426 exchange between anhydrous silicates and significantly less water than the other groups of

427 carbonaceous chondrites.

428 Magnetite and fayalite in MAC 88107 plot along a mass-dependent fractionation line

429 with $\delta^{17} \mathrm{O}=(0.48 \pm 0.02) \times \delta^{18} \mathrm{O}-(1.10 \pm 2.05)\left(\right.$ Fig. $\left.6 \mathrm{~B} ; \mathrm{r}^{2}=0.84, \mathrm{MSWD}=0.56\right)$,

430 interpreted as formation at isotopic equilibrium with the same fluid reservoir (Doyle et al.,

431 2015). Based on O-isotopic compositions and mineralogical, petrographic and

432 thermodynamic constraints, it has been proposed that fayalite and magnetite formed at low

433 water/rock ratios $(0.1-0.2)$ and relatively elevated temperature $\left(100-200^{\circ} \mathrm{C}\right.$; (Doyle et al.,

434 2015). However, considering the average $\delta^{18} \mathrm{O}$ values of magnetite and fayalite (i.e., $10.2 \pm$

$4351.3 \%$ and $14.1 \pm 0.6 \%$, respectively), the observed $\Delta^{18} \mathrm{O}_{\mathrm{mt}-\mathrm{Fa}}\left(=\delta^{18} \mathrm{O}_{\mathrm{mt}}-\delta^{18} \mathrm{O}_{\mathrm{Fa}}\right)$ rather

436 suggests a formation temperature of $480 \pm 20^{\circ} \mathrm{C}$ (Chacko et al., 2001). Considering even the 
437 larger $\Delta^{18} \mathrm{O}_{\mathrm{mt}-\mathrm{Fa}}$ (Doyle et al., 2015) leads to an estimate temperature of $\sim 250^{\circ} \mathrm{C}$, significantly 438 higher than that previously estimated for CO chondrites (i.e., 0-50 ${ }^{\circ} \mathrm{C}$ ) (Zolensky et al., 1993). 439 Whatever the alteration temperature of MAC 88107 , the fractionation factor $\alpha_{\text {Fa-water }}$ is 440 relatively small (i.e., $3.4 \%$ at $100^{\circ} \mathrm{C}$ and $-3.6 \%$ at $500^{\circ} \mathrm{C}$ ) (Zheng, 1993), allowing the final 441 O-isotopic composition of $\mathrm{CO}$ water to be computed at $\delta^{18} \mathrm{O}$ of $15 \pm 3.5 \%$. Although the bulk 442 O-isotopic composition of MAC 88107 has not been determined, it is possible to estimate the 443 water/rock ratio of $\mathrm{CO}$ chondrites by following some reasonable assumptions. Considering 444 that MAC 88107 likely has a bulk O-isotopic composition falling in the lower range observed 445 for $\mathrm{CO}$ chondrites (i.e., -4 to $-2 \%$ ) and assuming that COs have similar initial water and 446 anhydrous protolith as CMs (+30.3 and -4.2\%, respectively; (Clayton and Mayeda, 1984), 447 the water/rock estimated for MAC 88107 range from 0.01 to 0.10 . These values are consistent 448 with previous estimates (Zolensky et al., 1993) and the limited alteration of CO chondrites 449 relative to $\mathrm{CV}$ and $\mathrm{CM}$. However, it should be kept in mind that the lack of secondary phases 450 in $\mathrm{CO}$ chondrites makes this estimation less robust than those reported for $\mathrm{CM}, \mathrm{CR}$ and $\mathrm{CV}$ 451 chondrites.

\subsection{Implications for the structure and evolution of the accretion disk}

All carbonaceous chondrites show varying degrees of fluid alteration suggesting that water ice grains were significant components of their parent bodies. By combining bulk and mineral O-isotope data, we estimate the water/rock ratios of carbonaceous chondrites to be:

$\mathrm{CM}(0.3-0.4) \geq \mathrm{CR}(0.1-0.4) \geq \mathrm{CV}(0.1-0.2)>\mathrm{CO}(0.01-0.10)$ (Fig. 7). Our results suggest that water was heterogeneously distributed across the chondrite accretion regions. Current 460 debate considers carbonaceous chondrites formation either in the main asteroid belt 461 (Alexander et al., 2012) or in the outer Solar System (i.e., 5-15 UA) before subsequent 
Tack model; (Walsh et al., 2011). The low water/rock ratios estimated in this study support

464 carbonaceous chondrite accretion close to the snowline as accretion at greater heliocentric 465 distances would have induced a solar water/rock ratio of 1.2 (Lodders, 2003). The low carbonaceous chondrite water/rock ratios suggest that the snowline did not drift closer to the Sun than the inner edge of the asteroid belt (Morbidelli et al., 2016) and was probably located at 2-3 AU during the accretion of the carbonaceous asteroid, 2-4 My after the formation of CAIs (Krot et al., 2015).

The majority of secondary minerals in carbonaceous chondrites show O-isotopic signatures that are consistent with accretion of locally derived water from the inner Solar System. Such water presents minimal mass-independent $\mathrm{O}$-isotopic variations (i.e., $\Delta^{17} \mathrm{O} \sim$ $0 \%$, contrary to outer water ices enriched in ${ }^{17} \mathrm{O}$ - and ${ }^{18} \mathrm{O}\left(\Delta{ }^{17} \mathrm{O}>>0 \%\right)$, implying that water ice originating from the outer Solar System was not the main source for water in carbonaceous chondrites (Yurimoto and Kuramoto, 2004). This conclusion is consistent with D-poor compositions of carbonaceous chondrite waters (Alexander 2012, Piani 2017). Based on the expected heliocentric $\mathrm{D} / \mathrm{H}$ gradient ratio in the accretion disk (Jacquet and Robert, 2013), both H and O isotopes suggest an inner Solar System origin of water accreted into carbonaceous chondrite, probably where carbonaceous asteroids are located today (Alexander, 2017).

The low influx of ${ }^{17} \mathrm{O}$ - and ${ }^{18} \mathrm{O}$-rich and D-rich water ice from the outer part of the 482 Solar System may be due to the early growth of Jupiter $(\approx 1 \mathrm{My}$ after the start of the Solar System), which would have prevented inward radial drift in the protoplanetary disk (Walsh et al., 2011). An inner Solar System origin of carbonaceous chondrites is consistent wit their

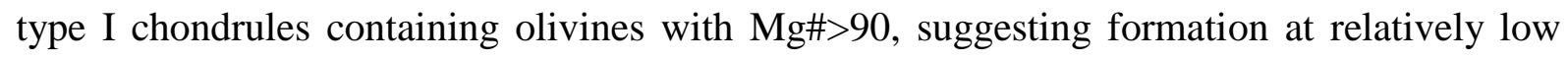
oxygen fugacity, whereas formation beyond the orbit of Jupiter should have occurred under more oxidizing conditions. Contrary to these conclusions, (Kruijer et al., 2017) attribute the 
molybdenum and tungsten isotopic compositions of iron meteorites derived from a

489 carbonaceous meteorite reservoir to a late addition of $\mathrm{W}$ - and Mo-bearing presolar material to

490 the outer Solar System. However, presolar grains (generally $<20 \mu \mathrm{m}$ in size), being tightly

491 coupled to gas motions (i.e., particles < $150 \mu \mathrm{m}$ in size; Fig. 8C) might have crossed Jupiter's

492 orbit and reached the inner Solar System (Zhu et al., 2012). As the carrier phases of Mo and

493 W isotope anomalies (Kruijer et al., 2017), presolar grains could have thus been preferentially

494 incorporated into asteroids accreting near the snow line, i.e. carbonaceous chondrites (Fig.

495 8D). Chondrites forming at smaller heliocentric distances and/or earlier in the history of the

496 protoplanetary disk would have incorporated a different population of presolar grains.

497 Ordinary chondrites are consistent with such an origin, as their potential earlier onset of

498 aqueous activity (Krot et al., 2015; Sugiura and Fujiya, 2014) as well as D-rich water and

499 organic matter relative to carbonaceous chondrites (Piani et al., 2015) could have resulted

500 from accretion before the Jupiter-induced gap in the protoplanetary disk. Additionally,

501 ordinary chondrites contain more type II chondrules characterized by low Mg\# olivines (i.e.,

$502 \mathrm{Mg \# <90)}$ than carbonaceous chondrites, indicating their formation in more oxidizing

503 environments.

504 Carbonaceous chondrites and their water are thus by-products of the evolution of the 505 inner Solar System. The O-isotopic composition of water produced via self-shielding 506 photodissociation decreases with time and increasing heliocentric distance in the accretion 507 disk, becoming similar to that observed in carbonaceous chondrites after 1 My (Yang et al., 508 2011). Consequently, the O-isotopic of water upon the accretion of hydrated carbonaceous 509 parent bodies (i.e., 2-4 Ma; (Sugiura and Fujiya, 2014) should have been smoothed toward 510 Earth-like values, potentially via re-equilibration with silicates in the disk (Alexander, 2017;

511 Yurimoto and Kuramoto, 2004). Inner solar water accreted by hydrated carbonaceous 512 asteroids may be ice condensed at the snow line and/or liquid water adsorbed at the grain 
surfaces. The increasing water/rock ratios of $\mathrm{CO}, \mathrm{CV}, \mathrm{CR}$, and $\mathrm{CM}$ reflects that these classes

514 of carbonaceous asteroids accreted near to the snow line, but at increasing heliocentric

515 distances. We note that some Ca-carbonates of the least altered CM chondrite Paris have 516 peculiar O-isotopic compositions suggesting accretion of few percent water ice grains 517 originating from the outer part of the Solar System (Vacher et al., 2016). This is supported by 518 the distinct $\mathrm{C} / \mathrm{H}$ vs. D/H correlation reported for the Paris' matrix compared to the other $\mathrm{CM}$ 519 chondrites (Piani et al., 2017). These results suggest limited but significant contribution of 520 outer Solar System materials to the chondrite-forming regions. Interestingly, CV chondrites 521 may have accreted ${ }^{17} \mathrm{O}$ - and ${ }^{18} \mathrm{O}$-rich water (i.e., $\Delta \Delta^{17} \mathrm{O}>15 \%$ ) during their formation $\approx 1 \mathrm{My}$ 522 before the more hydrated carbonaceous chondrites (Sugiura and Fujiya, 2014). It is possible 523 that inward radial mixing was more efficient at the time of $\mathrm{CV}$ chondrite accretion but 524 significantly decreased upon the formation of Jupiter, which limited later contribution of outer water ices in favor of locally derived water in the accretion zones of carbonaceous asteroids. fayalite grains in CV chondrites Kaba and Mokoia. When combined with both the bulk and matrix O-isotopic compositions of $\mathrm{CV}$ chondrites, their O-isotopic composition define the continuous trend $\delta^{17} \mathrm{O}=(0.84 \pm 0.03) \times \delta^{18} \mathrm{O}-(4.25 \pm 0.1)$. This implies that the process controlling the O-isotopic composition of the $\mathrm{CV}$ chondrite parent body was related to isotopic equilibrium between ${ }^{16} \mathrm{O}$-rich anhydrous silicates and ${ }^{17} \mathrm{O}$ - and ${ }^{18} \mathrm{O}$-rich fluid. Similar 536 behaviors are observed in $\mathrm{CM}, \mathrm{CR}$ and $\mathrm{CO}$ chondrites, demonstrating the ubiquitous nature of 537 O-isotopic exchange as the main physical process controlling the O-isotopic features of 538 carbonaceous chondrites, regardless of the extent of alteration. Based on these results, we 539 estimate the abundance of water accreted by carbonaceous chondrites (quantified by the 
water/rock ratio) to be $\mathrm{CM}(0.4) \geq \mathrm{CR}(0.1-0.4) \geq \mathrm{CV}(0.1-0.2)>\mathrm{CO}(0.01-0.10)$. This

541 suggests a heterogeneous distribution of water in the accretion zone of carbonaceous 542 asteroids. The relatively low water/rock ratios estimated for carbonaceous chondrites indicate 543 their accretion near the snowline, in the inner Solar System, as accretion further out in the 544 disk would have induced solar water/rock ratio of 1.2. Most of aqueously formed minerals in 545 carbonaceous chondrites show O-isotopic characteristics consistent with accretion of local 546 water, likely formed from the condensation of the gas near the snowline and/or liquid water 547 adsorbed at the grain surfaces. These results provide no evidence of carbonaceous chondrite 548 formation beyond the orbit of Jupiter and imply a limited influx of D- and ${ }^{17} \mathrm{O}$ - and ${ }^{18} \mathrm{O}$-rich 549 water ice grains from the outer part of the Solar System. Such a limited influx might result 550 from a gap in the solar protoplanetary disk due to the early and rapid formation of Jupiter, 551 which would limit the inward motion of particles with size higher than $150 \mu \mathrm{m}$. This model accounts for the $\mathrm{O}$ - and $\mathrm{H}$-isotopic signatures of carbonaceous chondrites, and suggest their accretion in the inner Solar System, closer to Jupiter than non-carbonaceous chondrites. Hence, carbonaceous chondrites would have preferentially accreted W- and Mo-bearing presolar grains crossing the orbit of Jupiter, resulting in significant lower W- and Mo556 anomalies in non-carbonaceous meteorites. Among carbonaceous chondrites, only CV 557 chondrites show O-isotopic features compatible with accretion of ${ }^{17-18}$ O-rich water, possibly related to their older accretion age relative to other hydrated carbonaceous chondrites.

\section{Acknowledgments}

562 All of the data used in the present article are available by contacting Yves Marrocchi (yvesm@crpg.cnrs-nancy.fr). Ludovic Ferrière and the National Museum History of Vienna

564 (Austria) are thanked for the loan of the Kaba and Mokoia sections. Matthieu Gounelle is 565 warmly thanked for helpful scientific discussions. Johan Villeneuve, Nordine Bouden, David 
Madre and Andrey Gurenko are thanked for their assistance with isotopic measurements This work was funded by l'Agence Nationale de la Recherche through grant ANR-14-CE33-0002-

01 SAPINS (PI Yves Marrocchi). We thanked three anonymous reviewers for constructive contribution \#2517 and SAPINS contribution \#10.

\section{$571 \quad$ Figure Caption}

Fig. 1: Back-scattered electron micrographs of fayalite grains in the Kaba CV chondrite.

(A) Fayalite grains located in the chondrule rim in association with iron sulfides and isolated in the matrix. $\mathrm{OA}=$ opaque assemblage. (B) Sulfide- and magnetite-free fayalite grain commonly observed in the Kaba and Mokoia matrices.

Fig. 2: Oxygen three-isotope plot for bulk and matrix CV chondrites (Clayton and Mayeda, 1999; 1984; Greenwood et al., 2010) and sulfide- and magnetite-free fayalite grains from Mokoia and Kaba. Oxygen isotopic variations are expressed in delta units as deviations of the ${ }^{17} \mathrm{O} /{ }^{16} \mathrm{O}$ and ${ }^{18} \mathrm{O} /{ }^{16} \mathrm{O}$ isotopic ratios relative to the $\mathrm{V}$-SMOW international standard $\left(\delta^{\mathrm{X}} \mathrm{O}=\left({ }^{\mathrm{X}} \mathrm{O} /{ }^{16} \mathrm{O} /{ }^{\mathrm{X}} \mathrm{O}^{16} \mathrm{O}_{\mathrm{V}-\mathrm{SmOw}}-1\right) \times 1000 ; \mathrm{x}={ }^{18} \mathrm{O}\right.$ or $\left.{ }^{17} \mathrm{O}\right)$. Two different lines $(\mathrm{PCM}=$ Primary in CV chondrite A-881317 (Doyle et al., 2015) and Kaba ((Krot and Nagashima, 2016), corresponding to $*$ in the figure caption) are also represented. $\mathrm{CV}$ water corresponds to the $\mathrm{O}$ -

586 isotopic composition from which fayalite grains have precipitated according to the 587 fractionation factor $\alpha$ (Zheng, 1993). Uncertainties shown are $2 \sigma$. (B) $\Delta^{17} \mathrm{O}$ values (see text) 588 of bulk, matrix and fayalite in CV chondrites. The data are plotted arbitrarily along the x-axis. 589 Uncertainties shown are $2 \sigma$. 
591 Fig. 3: (A) Oxygen three-isotope plot for bulk and matrix CV chondrites ((Clayton and 592 Mayeda, 1999; 1984)) and fayalite grains from Mokoia, Kaba and A-881317 (Doyle et al., 593 2015). The O-isotopic composition of magnetite in Kaba chondrules (Marrocchi et al., 2016) 594 and in the matrix of A-881317 (Doyle et al., 2015) and Kaba (Krot and Nagashima, 2016) are 595 also represented. Uncertainties shown are $2 \sigma$. (B) $\Delta^{17} \mathrm{O}$ values of bulk, matrix, fayalite and 596 magnetite in the $\mathrm{CV}$ chondrites Kaba, Mokoia and A881317. The similar $\Delta^{17} \mathrm{O}$ observed 597 between fayalite and magnetite in A-881317 indicate that they probably formed at isotopic 598 equilibrium from the same fluid reservoir. To the contrary, fayalite and magnetite in Kaba 599 show significantly different $\Delta^{17} \mathrm{O}$ that could be linked to the formation of magnetite during 600 the high-temperature chondrule-forming event (Marrocchi et al., 2016). Uncertainties shown 601 are $2 \sigma$.

602

Fig. 4: (A) Oxygen three-isotope plot of Ca-carbonates in CM chondrites Murchison and 604 Mighei (Lindgren et al., 2017). The O-isotopic compositions of Ca-carbonates define the trend $\delta^{17} \mathrm{O}=(0.70 \pm 0.03) \times \delta^{18} \mathrm{O}-(5.65 \pm 1.25)$, similar, within errors, to that reported for 9 different CM chondrites (Verdier-Paoletti et al., 2017). The O-isotopic compositions of CM alteration water inferred from direct measurements and mass balance calculations define a continuous trend, parallel within errors to that shown by bulk CMs and Ca-carbonates, but 609 with a different intercept $\left(\delta^{17} \mathrm{O}=(0.69 \pm 0.02) \times \delta^{18} \mathrm{O}-(2.12 \pm 0.30)\right)$. As both trends are 610 parallel, the temperature of carbonate precipitation can be determined (see text). Uncertainties 611 shown are $2 \sigma$. (B) $\Delta^{17} \mathrm{O}$ values of inferred $\mathrm{CM}$ water showing the near terrestrial values of 612 water accreted by CM chondrites. Uncertainties shown are $2 \sigma$

614 Fig. 5: (A) Oxygen three-isotope plot of bulk, matrix and Ca-carbonates of CR chondrites 615 (Clayton and Mayeda, 1999; Jilly, 2015; Jilly et al., 2014; Schrader et al., 2011). The O- 
616 isotopic compositions of $\mathrm{CR}$ alteration water from which Ca-carbonates precipitated are also

617 represented. CR water O-isotopic compositions were calculated based on the isotopic 618 equilibrium between Ca-carbonates and magnetite per CR chondrite (represented in panel (B); 619 data from Jilly, 2015). Uncertainties shown are $2 \sigma$.

620

621 Fig. 6: (A) Oxygen three-isotope plot of bulk and matrix in $\mathrm{CO}$ chondrites (Clayton and 622 Mayeda, 1999). The O-isotopic compositions of fayalite grains in CO-like MacAlpine Hills 62388107 are also represented (Doyle et al., 2015). Together, the data define the continuous trend 624 with $\delta^{17} \mathrm{O}=(0.68 \pm 0.08) \times \delta^{18} \mathrm{O}-(4.08 \pm 0.14)$. CO water corresponds to the O-isotopic 625 composition from which fayalite grains precipitated according to the fractionation factor $\alpha$ 626 between fayalite and water (Zheng, 1993). Uncertainties shown are $2 \sigma$. (B) Oxygen isotopic compositions of magnetite and fayalite in CO-like chondrite MacAlpine Hills 88107 (Doyle et al., 2015) plot on a mass-dependent fractionation line, allowing the alteration temperature and the O-isotopic composition of the alteration water of this chondrite to be determined (CO water; see text for details). Uncertainties shown are $2 \sigma$.

Fig. 7: Schematic representation of the water/rock ratio estimated for the $\mathrm{CO}, \mathrm{CV}, \mathrm{CR}$ and 633 CM chondrites.

Fig. 8: A) Coexistence and spatial separation of non-carbonaceous chondrite (NCC) and carbonaceous chondrite (CC) reservoirs as depicted by (Kruijer et al., 2017). The early 637 formation of Jupiter ( $1 \mathrm{Ma}$ after the formation of the Solar System) would have acted as a 638 barrier against inward transport of solids across the disk, and thus mixing of the CC and NCC 639 reservoirs. (B) Key observables of the oxygen and hydrogen isotopic compositions in the 640 protoplanetary disk are at odds with the model proposed by (Kruijer et al., 2017). 
641 (C) Scenario proposed herein for the preservation of ${ }^{16} \mathrm{O}$-rich and D-poor water in the inner 642 solar system. Jupiter would have acted as a barrier precluding significant inward transport of 643 outer Solar System water toward the inner Solar System. (D) Scenario proposed in this study 644 for the accretion of ${ }^{16} \mathrm{O}$-rich and D-poor water by hydrated carbonaceous asteroids. The 645 increasing water/rock ratios of $\mathrm{CO}, \mathrm{CV}, \mathrm{CR}$ and $\mathrm{CM}$ chondrites reflect that these different 646 types of carbonaceous asteroids accreted close to the snow line, at increasing heliocentric 647 distances.

648 

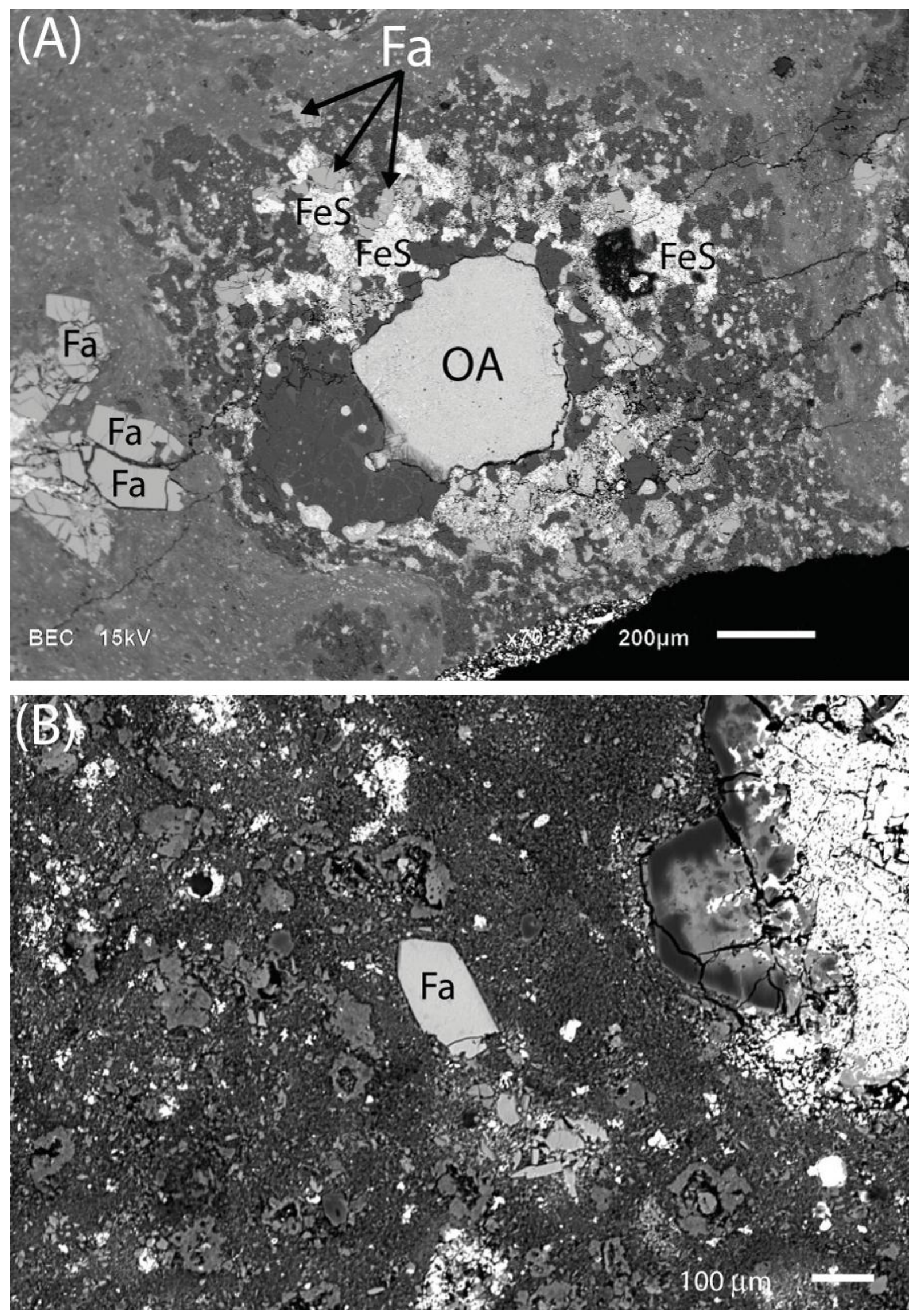

651

Fig. 1

652 

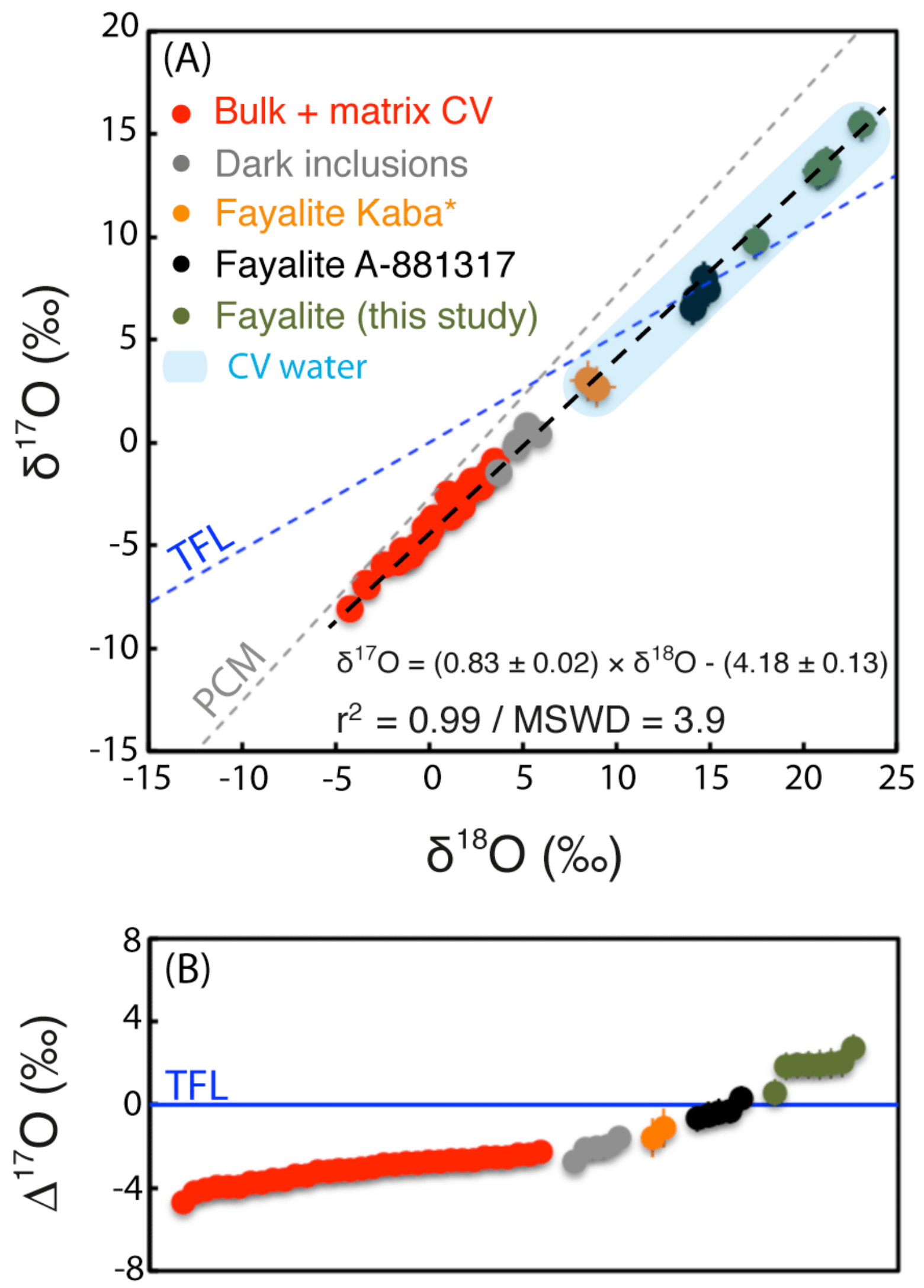

Fig. 2 

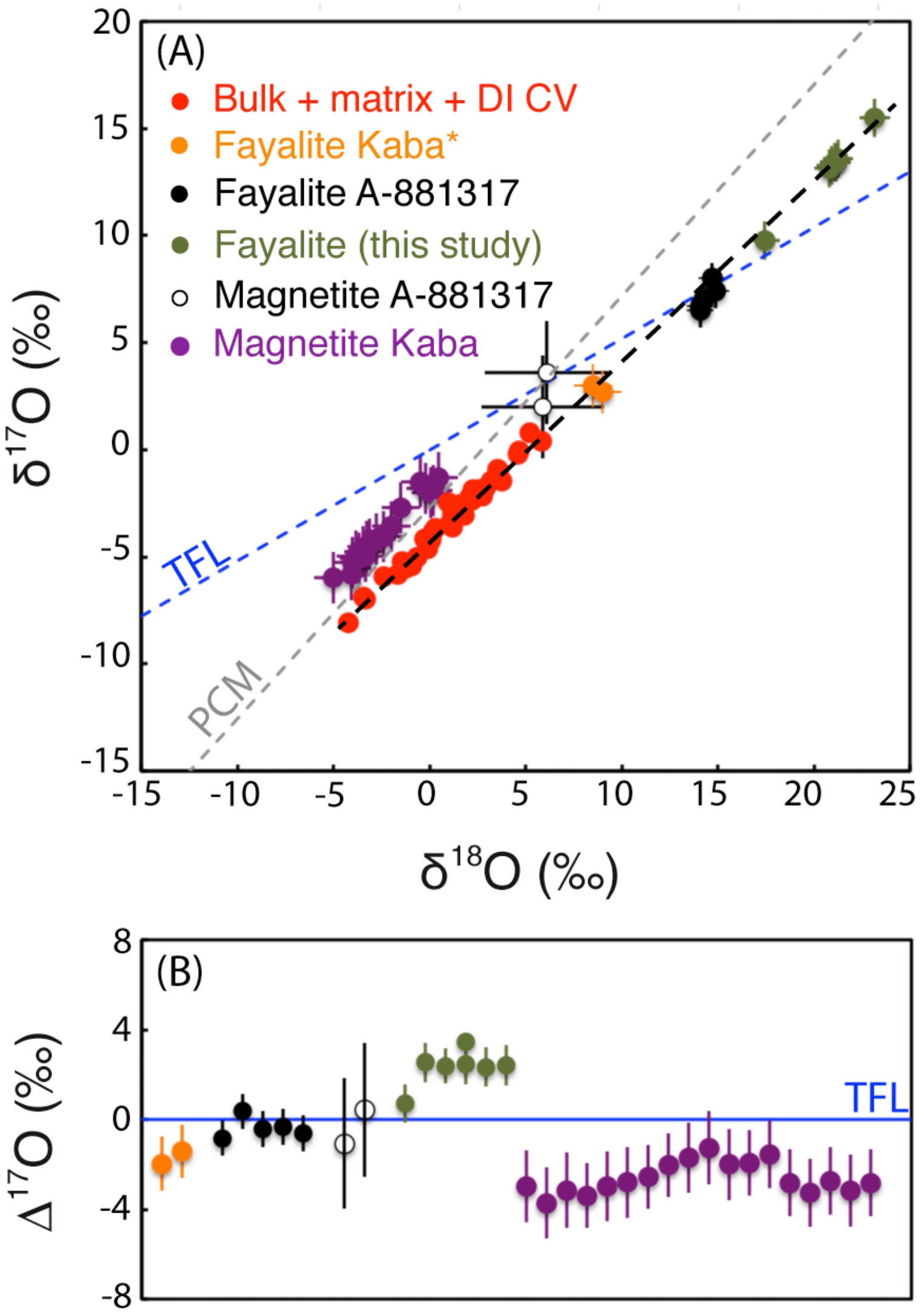

Fig. 3 

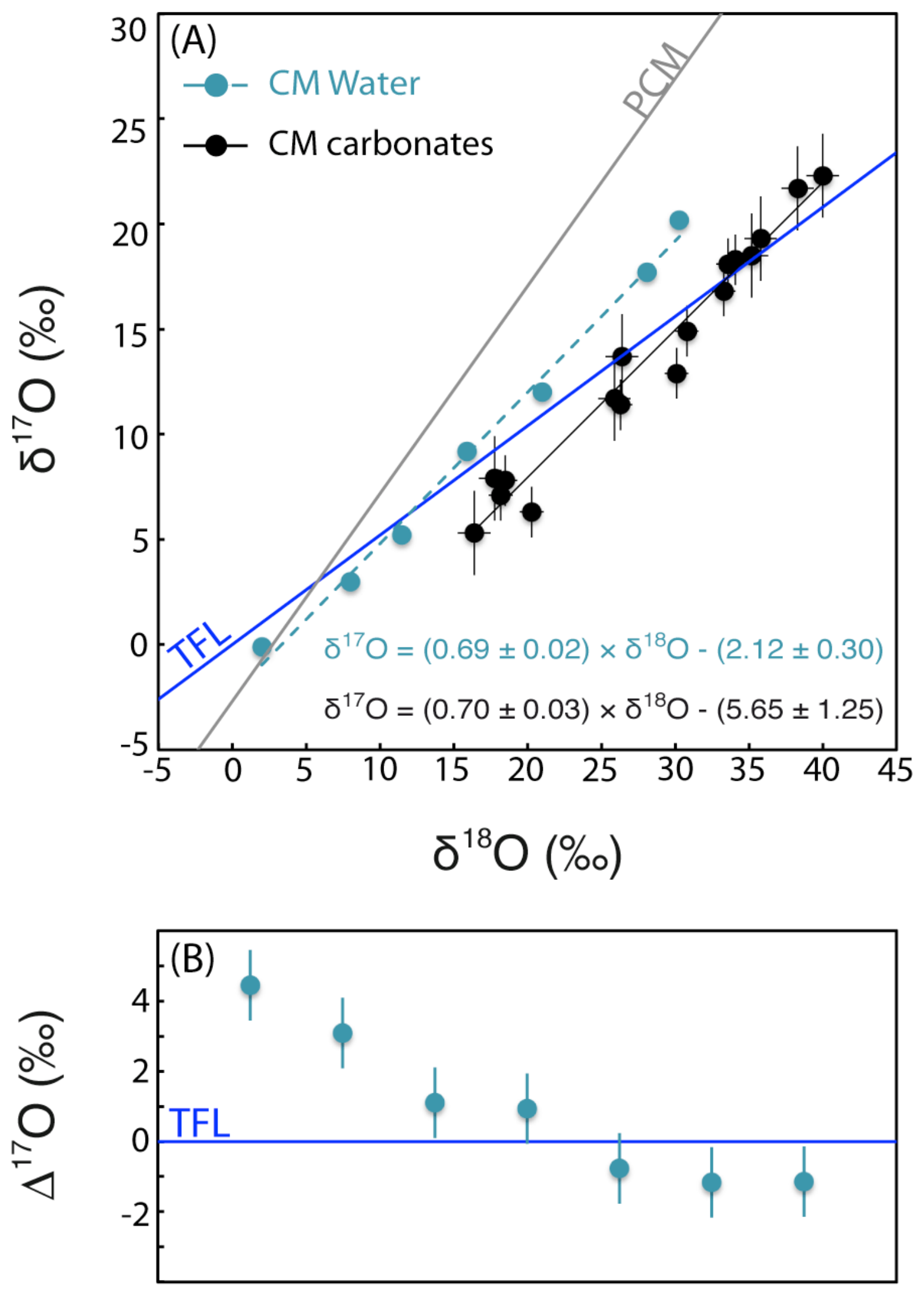

Fig. 4 

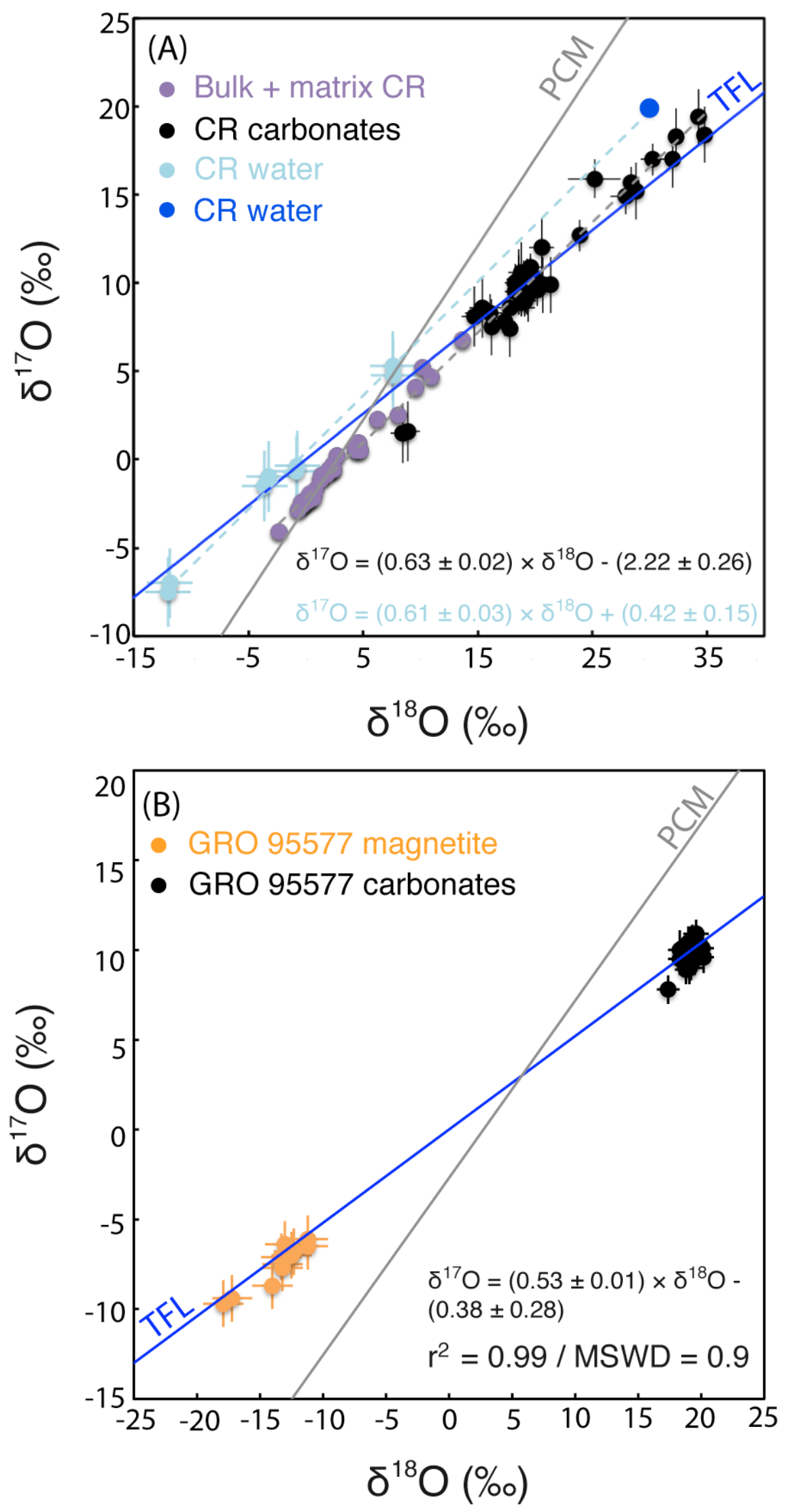

666
667

668

Fig. 5 

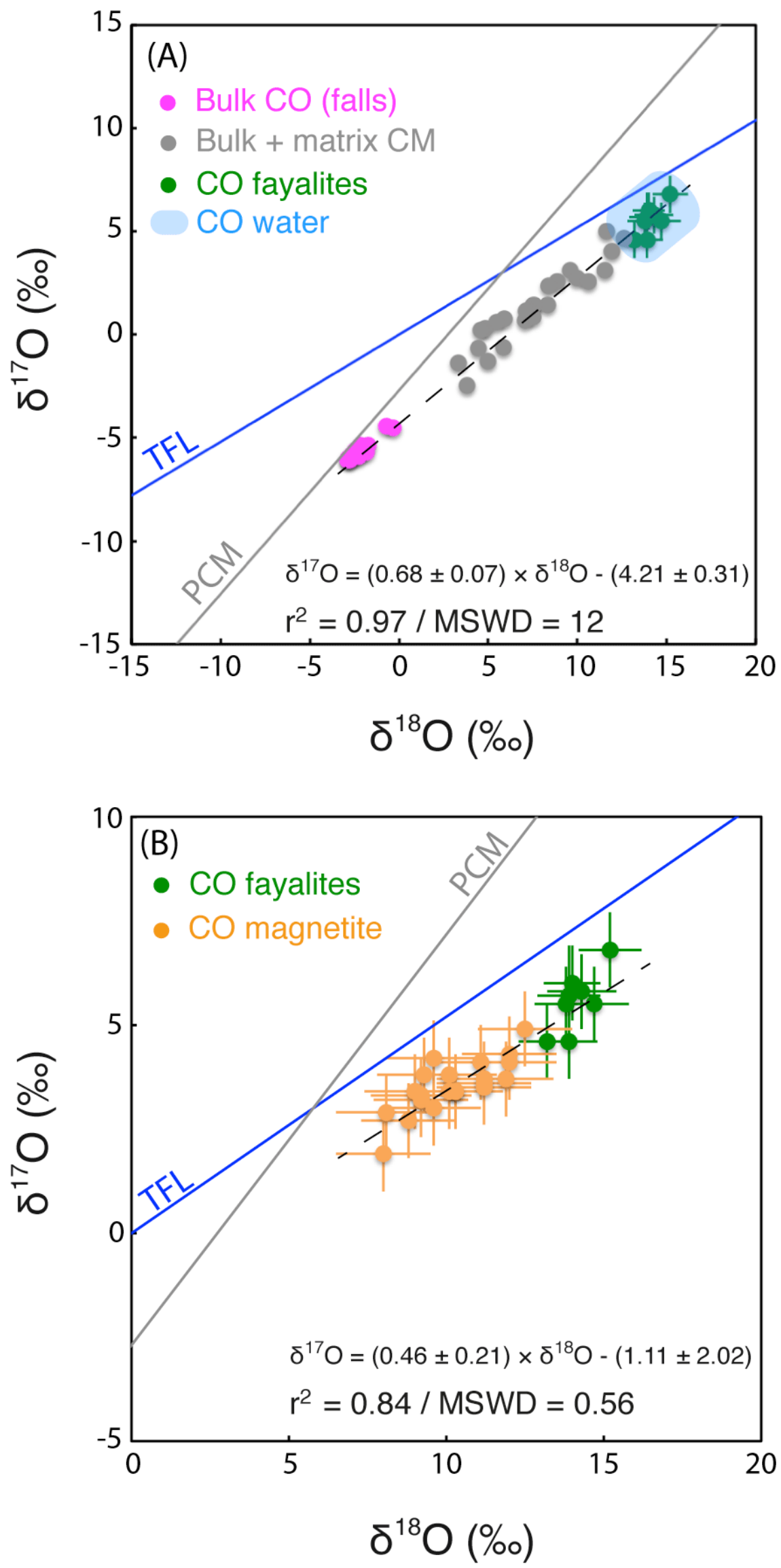

Fig. 6 
671

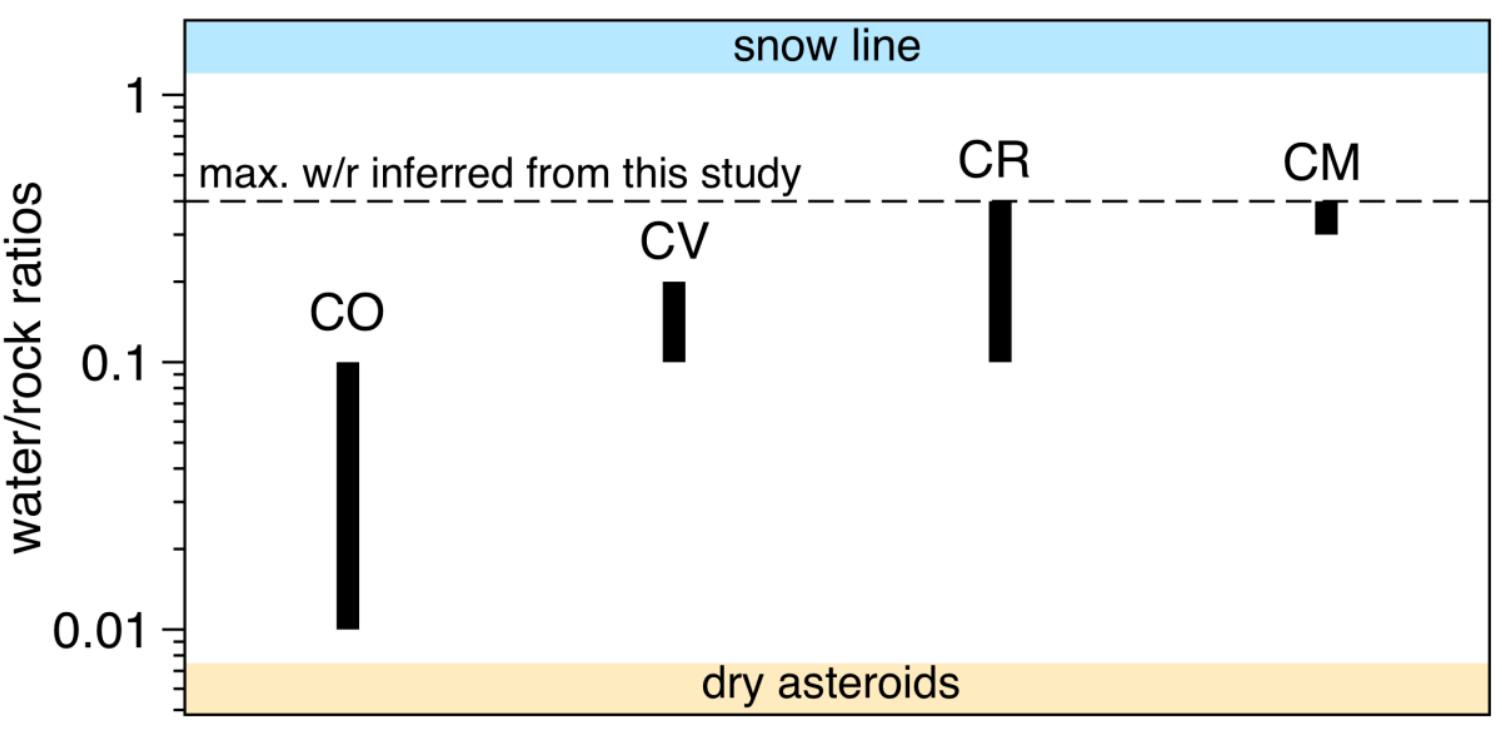

672

673

Fig. 7

674

675

676

677

678

679

680

681

682

683

684

685 

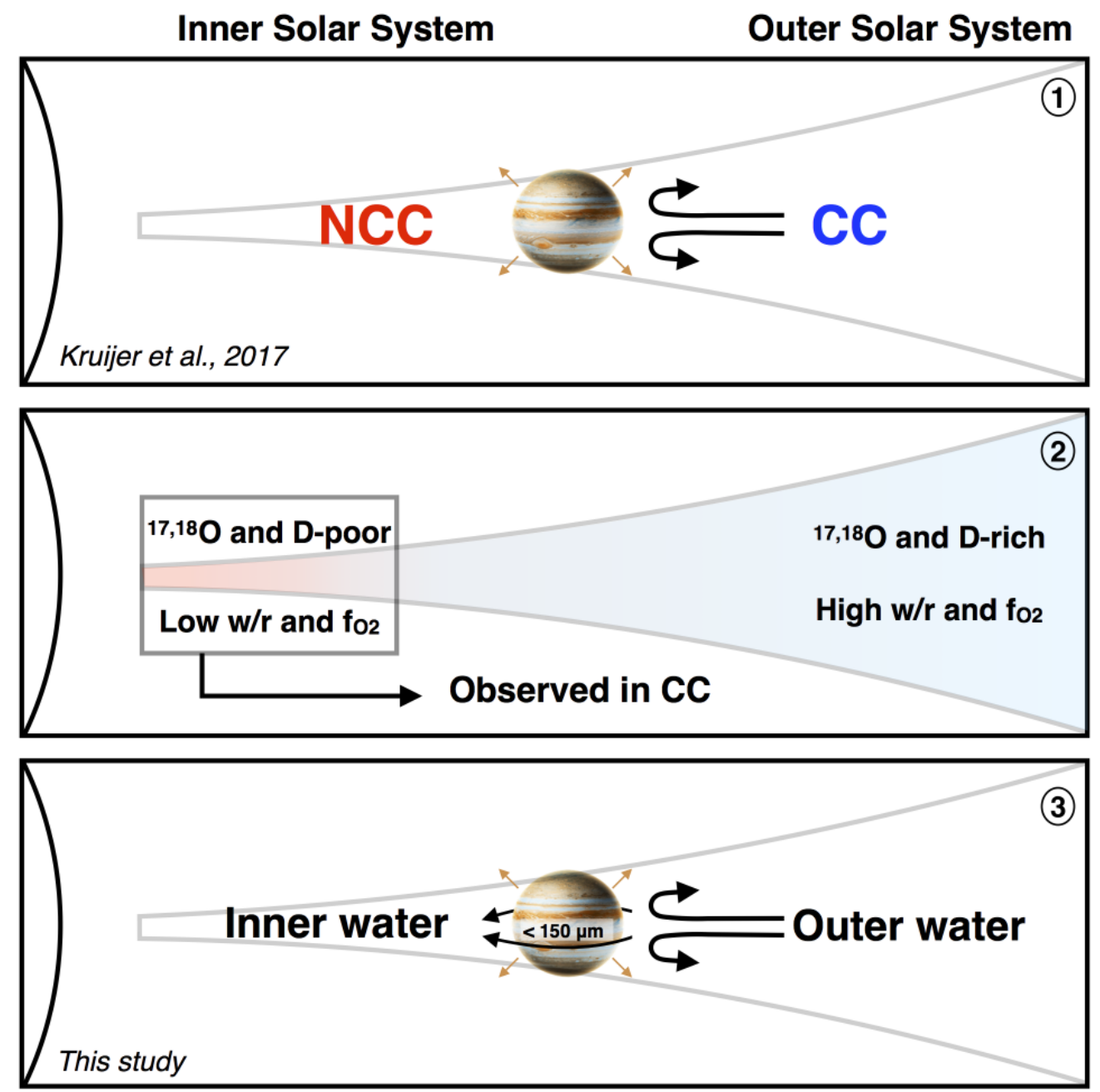
Inner water

CO CV CR CM 17,18O and D-poor Low w/r and fo2

Fig. 8 


\begin{tabular}{|c|c|c|c|c|c|c|c|c|c|c|c|c|c|}
\hline chondrite & point & $\mathrm{SiO}_{2}$ & $\mathrm{~K}_{2} \mathrm{O}$ & $\mathrm{FeO}$ & $\mathrm{Na}_{2} \mathrm{O}$ & $\mathrm{Al}_{2} \mathrm{O}_{3}$ & $\mathrm{CaO}$ & $\mathrm{MnO}$ & $\mathrm{MgO}$ & $\mathrm{Cr}_{2} \mathrm{O}_{3}$ & $\mathrm{TiO}_{2}$ & Total & $\mathrm{Fa}$ \\
\hline \multirow[t]{6}{*}{ Kaba } & Fa-1 & 29.3 & bdl & 69.1 & bdl & bdl & bdl & 0.7 & 0.8 & bdl & bdl & 99.9 & 98.9 \\
\hline & Fa-2 & 29.4 & bdl & 69.4 & bdl & bdl & bdl & 0.4 & 0.6 & bdl & bdl & 99.7 & 99.2 \\
\hline & $\mathrm{Fa}-3$ & 29.2 & bdl & 69.2 & bdl & bdl & bdl & 0.7 & 0.5 & bdl & bdl & 99.7 & 99.2 \\
\hline & $\mathrm{Fa}-4$ & 29.0 & bdl & 69.6 & bdl & bdl & bdl & 0.7 & 0.0 & bdl & bdl & 99.4 & 100.0 \\
\hline & $\mathrm{Fa}-5$ & 29.8 & bdl & 67.1 & bdl & bdl & bdl & 0.8 & 2.1 & bdl & bdl & 99.7 & 97.0 \\
\hline & Fa-6 & 29.5 & bdl & 68.2 & bdl & bdl & bdl & 1.2 & 0.8 & bdl & bdl & 99.6 & 98.9 \\
\hline \multirow[t]{2}{*}{ Mokoia } & Fa-7 & 29.2 & bdl & 68.8 & bdl & bdl & bdl & 0.6 & 1.2 & bdl & bdl & 99.8 & 98.3 \\
\hline & $\mathrm{Fa}-8$ & 28.9 & bdl & 68.1 & bdl & bdl & bdl & 0.9 & 1.8 & bdl & bdl & 99.7 & 97.4 \\
\hline
\end{tabular}

Table 1: Chemical composition and Fa\# of fayalite grains observed in the Kaba and Mokoia CV chondrites 


\begin{tabular}{cccccccc}
\hline chondrite & point & ${ }^{18} \mathrm{O}$ & 2 & ${ }^{17} \mathrm{O}$ & 2 & ${ }^{17} \mathrm{O}$ & 2 \\
\hline \hline \multirow{5}{*}{ Kaba } & & & & & & & \\
& Fa-1 & 17.4 & 0.8 & 9.8 & 0.9 & 0.7 & 0.9 \\
& Fa-2 & 21.3 & 0.8 & 13.6 & 0.9 & 2.5 & 0.9 \\
& Fa-3 & 20.9 & 0.8 & 13.3 & 0.9 & 2.4 & 0.8 \\
& Fa-4 & 21.1 & 0.8 & 13.4 & 0.9 & 2.5 & 0.9 \\
& Fa-5 & 20.8 & 0.8 & 13.2 & 0.9 & 2.3 & 0.9 \\
& Fa-6 & 21.2 & 0.8 & 13.4 & 0.9 & 2.4 & 0.9 \\
Mokoia & Fa-7 & 23.2 & 0.8 & 15.5 & 0.9 & 3.5 & 0.8 \\
& Fa-8 & 20.8 & 0.8 & 13.2 & 0.9 & 2.4 & 0.9 \\
& & & & & & & \\
\hline
\end{tabular}

Table 2: Oxygen isotopic composition of fayalite grains in the Kaba and Mokoia CV chondrites. Uncertainties reported are $2 \sigma$. 


\section{References}

Albarède, F., 2009. Volatile accretion history of the terrestrial planets and dynamic implications. Nature 461, 1227-1233. doi:10.1038/nature08477

Alexander, C.M.O., 2017. The origin of inner Solar System water. Philosophical Transactions of the Royal Society A: Mathematical, Physical and Engineering Sciences 375, 20150384-20. doi:10.1098/rsta.2015.0384

Alexander, C.M.O'D, Bowden, R., Fogel, M.L., Howard, K.T., Herd, C.D.K., Nittler, L.R., 2012. The Provenances of Asteroids, and Their Contributions to the Volatile Inventories of the Terrestrial Planets. Science 337, 721-723. doi:10.1126/science.1223474

Alexander, C.M.O'D, Greenwood, R.C., Bowden, R., Gibson, J.M., Howard, K.T., Franchi, I.A., 2017. A mutli-technique search for the most primitive CO chondrites. Geochim. Cosmochim. Acta 1-15. doi:10.1016/j.gca.2017.04.021

Bitsch, B., Johansen, A., Lambrechts, M., Morbidelli, A., 2015. The structure of protoplanetary discs around evolving young stars. A\&A 575, A28-17. doi:10.1051/00046361/201424964

Bland, P.A., Jackson, M.D., Coker, R.F., Cohen, B.A., Webber, J.B.W., Lee, M.R., Duffy, C.M., Chater, R.J., Ardakani, M.G., McPhail, D.S., McComb, D.W., Benedix, G.K., 2009. Why aqueous alteration in asteroids was isochemical: High porosity $\neq$ high permeability. Earth Planet. Sci. Lett. 287, 559-568. doi:10.1016/j.eps1.2009.09.004

Bonal, L., Quirico, E., Bourot-Denise, M., Montagnac, G., 2006. Determination of the petrologic type of CV3 chondrites by Raman spectroscopy of included organic matter. Geochim. Cosmochim. Acta 70, 1849-1863. doi:10.1016/j.gca.2005.12.004

Brearley, A.J., 2006. The action of water. Meteorites and the early solar system II. Edited by Lauretta D. S. and McSween H. Y. Tucson, Arizona: The University of Arizona Press. pp. 587-624.

Chacko, T., Cole, D.R., Horita, J., 2001. Equilibrium Oxygen, Hydrogen and Carbon Isotope Fractionation Factors Applicable to Geologic Systems. Reviews in Mineralogy and Geochemistry 43, 1-81. doi:10.2138/gsrmg.43.1.1

Choi, B.-G., Krot, A.N., Wasson, J.T., 2000. Oxygen isotopes in magnetite and fayalite in CV chondrites Kaba and Mokoia. Meteoritics \& Planetary Science 35, 1239-1248. doi:10.1111/j.1945-5100.2000.tb01512.x

Clayton, R.N., Grossman, L., Mayeda, T.K., 1973. A Component of Primitive Nuclear Composition in Carbonaceous Meteorites. Science 182, 485-488. doi:10.1126/science. 182.4111 .485

Clayton, R.N., Mayeda, T.K., 1999. Oxygen isotope studies of carbonaceous chondrites. Geochim. Cosmochim. Acta 63, 2089-2104. doi:10.1016/s0016-7037(99)00090-3

Clayton, R.N., Mayeda, T.K., 1984. The oxygen isotope record in Murchison and other carbonaceous chondrites. Earth and Planetary Science Letters 67, 151-161. doi:10.1016/0012-821x(84)90110-9

Doyle, P.M., Jogo, K., Nagashima, K., Krot, A.N., Wakita, S., Ciesla, F.J., Hutcheon, I.D., 2015. Early aqueous activity on the ordinary and carbonaceous chondrite parent bodies recorded by fayalite. Nat Comms 6, 7444. doi:10.1038/ncomms8444

Garenne, A., Beck, P., Montes-Hernandez, G., Chiriac, R., Toche, F., Quirico, E., Bonal, L., Schmitt, B., 2014. The abundance and stability of "water" in type 1 and 2 carbonaceous chondrites (CI, CM and CR). Geochim. Cosmochim. Acta 137, 93-112. doi:10.1016/j.gca.2014.03.034

Greenwood, R.C., Franchi, I.A., 2004. Alteration and metamorphism of CO3 chondrites: Evidence from oxygen and carbon isotopes. Meteoritics \& Planetary Science 39, 18231838. doi:10.1111/j.1945-5100.2004.tb00078.x 
Greenwood, R.C., Franchi, I.A., Kearsley, A.T., Alard, O., 2010. The relationship between CK and CV chondrites. Geochim. Cosmochim. Acta 74, 1684-1705. doi:10.1016/j.gca.2009.11.029

Gundlach, B., Blum, J., 2015. The stickiness of micrometer-sied water-ce particles. The Astrophys. J. 798, 34-12. doi:10.1088/0004-637X/798/1/34

Güttler, C., Blum, J., Zsom, A., Ormel, C.W., Dullemond, C.P., 2010. The outcome of protoplanetary dust growth: pebbles, boulders, or planetesimals? A\&A 513, A56-16. doi:10.1051/0004-6361/200912852

Hartmann, L., Calvet, N., Gullbring, E., D'Alessio, P., 1998. Accretion and the Evolution of T-Tauri Disks. The Astrophysical Journal. 495, 385-400. doi:10.1086/305277

Hewins, R.H., Bourot-Denise, M., Zanda, B., Leroux, H., Barrat, J.-A., Humayun, M., Göpel, C., Greenwood, R.C., Franchi, I.A., Pont, S., Lorand, J.-P., Cournède, C., Gattacceca, J., Rochette, P., Kuga, M., Marrocchi, Y., Marty, B., 2014. The Paris meteorite, the least altered CM chondrite so far. Geochim. Cosmochim. Acta 124, 190-222. doi:10.1016/j.gca.2013.09.014

Hua, X., Buseck, P.R., 1995. Fayalite in the Kaba and Mokoia carbonaceous chondrites. Geochim. Cosmochim. Acta 59, 563-578. doi:10.1016/0016-7037(94)00383-w

Jacquet, E., Robert, F., 2013. Water transport in protoplanetary disks and the hydrogen isotopic composition of chondrites. Icarus 223, 722-732. doi:10.1016/j.icarus.2013.01.022

Jilly, C.E., 2015. Timescales and conditions for the aqueous alteration of chondrites.

Dissertation of the university of hawai' $i$.

Jilly, C.E., Huss, G.R., Nagashima, K., 2014. Oxygen isotope fractionation among secondary calcite and magnetite in CR chondrites. $45^{\text {th }}$ Lunar and Planetary Science Conference, Houston, USA. Abstract \# 1642.

Jogo, K., Nakamura, T., Noguchi, T., Zolotov, M.Y., 2009. Fayalite in the Vigarano CV3 carbonaceous chondrite: Occurrences, formation age and conditions. Earth and Planetary Science Letters 287, 320-328. doi:10.1016/j.eps1.2009.08.014

Krot, A.N., Brearley, A.J., Petaev, M.I., Kallemeyn, G.W., Sears, D.W.G., Benoit, P.H., Hutcheon, I.D., Zolensky, M.E., Keil, K., 2000. Evidence for low- temperature growth of fayalite and hedenbergite in MacAlpine Hills 88107, an ungrouped carbonaceous chondrite related to the CM- CO clan. Meteoritics \& Planetary Science 35, 1365-1386. doi:10.1111/j.1945-5100.2000.tb01522.x

Krot, A.N., Nagashima, K., 2016. Evidence for oxygen-isotope exchange in chondrules and refractory inclusions during fluid-rock interaction on the CV chondrite parent body. 79th Annual Meeting of the Meteoritical Society, Berlin, Germany. LPI Contribution No. 1921, id.6014

Krot, A.N., Nagashima, K., Alexander, C.M.O'D, Ciesla, F.J., Fujiya, W., Bonal, L., 2015. Sources of Water and Aqueous Activity on the Chondrite Parent Asteroids, in: Asteroids IV. University of Arizona Press, pp. 1-27. doi:10.2458/azu_uapress_9780816532131ch033

Kruijer, T.S., Burkhardt, C., Budde, G., Kleine, T., 2017. Age of Jupiter inferred from the distinct genetics and formation times of meteorites. Proceedings of the National Academy of Sciences 201704461. doi:10.1073/pnas.1704461114

Le Guillou, C., Brearley, A., 2014. Relationships between organics, water and early stages of aqueous alteration in the pristine CR3.0 chondrite MET 00426. Geochim. Cosmochim. Acta 131, 344-367. doi:10.1016/j.gca.2013.10.024

Lindgren, P., Lee, M.R., Starkey, N.A., Franchi, I.A., 2017. Fluid evolution in CM carbonaceous chondrites tracked through the oxygen isotopic compositions of carbonates. 
Geochim. Cosmochim. Acta 204, 240-251. doi:10.1016/j.gca.2017.01.048

Lodders, K., 2003. Solar system abundances and condensation temperatures of the elements. Astrophys. J. 591, 1220-1247. doi:10.1086/375492

Marrocchi, Y., Chaussidon, M., Piani, L., Libourel, G., 2016. Early scattering of the solar protoplanetary disk recorded in meteoritic chondrules. Science Advances 2, e1601001e1601001. doi:10.1126/sciadv.1601001

Marrocchi, Y., Libourel, G., 2013. Sulfur and sulfides in chondrules. Geochim. Cosmochim. Acta 119, 117-136. doi:10.1016/j.gca.2013.05.020

Marty, B., 2012. The origins and concentrations of water, carbon, nitrogen and noble gases on Earth. Earth Planet. Sci. Lett. 313-314, 56-66. doi:10.1016/j.epsl.2011.10.040

Morbidelli, A., Bitsch, B., CRIDA, A., Gounelle, M., Guillot, T., Jacobson, S., Johansen, A., Lambrechts, M., Lega, E., 2016. Fossilized condensation lines in the Solar System protoplanetary disk. Icarus 267, 368-376. doi:10.1016/j.icarus.2015.11.027

Morlok, A., Libourel, G., 2013. Aqueous alteration in CR chondrites: Meteorite parent body processes as analogue for long-term corrosion processes relevant for nuclear waste disposal. Geochim. Cosmochim. Acta 103, 76-103. doi:10.1016/j.gca.2012.10.030

Oka, A., Nakamoto, T., Ida, S., 2011. Evolution of snowline in optically thick protoplanetary disks: Effects of water ice opacity and dust grain size. Astrophys. J. 738, 141-11. doi:10.1088/0004-637X/738/2/141

Piani, L., Robert, F., Beyssac, O., Binet L., Bourot-Denise, M., Derenne, S., Guillou, C.L., Marrocchi, Y., Mostefaoui, S., Rouzaud, J.-N., Thomen, A., 2011. Structure, composition, and location of organic matter in the enstatite chondrite Sahara 97096 (EH3). Meteoritics \& Planetary Science 47, 8-29. doi:10.1111/j.1945-5100.2011.01306.x

Piani, L., Robert, F., Remusat, L., 2015. Micron-scale D/H heterogeneity in chondrite matrices: A signature of the pristine solar system water? Earth Planet. Sci. Lett. 415, 154164. doi:10.1016/j.epsl.2015.01.039

Piani, L., Yurimoto, H., Remusat, L., 2017. A Dual Origin for Water in the CM Carbonaceous Chondrites. $48^{\text {th }}$ Lunar and Planetary Science Conference, Houston, USA. Abstract \# 1203.

Ros, K., Johansen, A., 2013. Ice condensation as a planet formation mechanism. A\&A 552, A137-14. doi:10.1051/0004-6361/201220536

Sakamoto, N., Seto, Y., Itoh, S., Kuramoto, K., Fujino, K., Nagashima, K., Krot, A.N., Yurimoto, H., 2007. Remnants of the Early Solar System Water Enriched in Heavy Oxygen Isotopes. Science 317, 231-233. doi:10.1126/science.1142021

Schrader, D.L., Davidson, J., 2017. CM and CO chondrites: A common parent body or asteroidal neighbors? Insights from chondrule silicates. Geochim. Cosmochim. Acta 214, 157-171. doi:10.1016/j.gca.2017.07.031

Schrader, D.L., Franchi, I.A., Connolly, H.C., Jr, Greenwood, R.C., Lauretta, D.S., Gibson, J.M., 2011. The formation and alteration of the Renazzo-like carbonaceous chondrites I: Implications of bulk-oxygen isotopic composition. Geochim. Cosmochim. Acta 75, 308325. doi:10.1016/j.gca.2010.09.028

Seto, Y., Sakamoto, N., Fujino, K., Kaito, T., Oikawa, T., Yurimoto, H., 2008. Mineralogical characterization of a unique material having heavy oxygen isotope anomaly in matrix of the primitive carbonaceous chondrite Acfer 094. Geochim. Cosmochim. Acta 72, $2723-$ 2734. doi:10.1016/j.gca.2008.03.010

Sugiura, N., Fujiya, W., 2014. Correlated accretion ages and $\varepsilon 54 \mathrm{Cr}$ of meteorite parent bodies and the evolution of the solar nebula. Meteorit Planet Sci 49, 772-787. doi:10.1111/maps.12292

Vacher, L.G., Marrocchi, Y., Verdier-Paoletti, M.J., Villeneuve, J., Gounelle, M., 2016. Inward radial mixing of interstellar water ices in the Solar protoplanetary disk. The 
Astrophysical Journal Letters 827, 1-6. doi:10.3847/2041-8205/827/1/L1

Vacher, L.G., Marrocchi, Y., Villeneuve, J., Verdier-Paoletti, M.J., Gounelle, M., 2017. Petrographic and $\mathrm{C} \& \mathrm{O}$ isotopic characteristics of the earliest stages of aqueous alteration of CM chondrites. Geochim. Cosmochim. Acta 213, 271-290. doi:10.1016/j.gca.2017.06.049

Verdier-Paoletti, M.J., Marrocchi, Y., Avice, G., Roskosz, M., Gurenko, A., Gounelle, M., 2017. Oxygen isotope constraints on the alteration temperatures of CM chondrites. Earth Planet. Sci. Lett. 458, 273-281. doi:10.1016/j.eps1.2016.10.055

Walsh, K.J., Morbidelli, A., Raymond, S.N., O’Brien, D.P., Mandell, A.M., 2011. A low mass for Mars from Jupiter's early gas-driven migration. Nature 475, 206-209. doi:10.1038/nature 10201

Yang, L., Ciesla, F.J., Lyons, J.R., Lee, J.E., 2011. Oxygen isotope anomalies in the solar nebula inherited from the proto-solar cloud. $42^{\text {th }}$ Lunar and Planetary Science Conference, Houston, USA. Abstract \# 1602.

Young, E.D., Ash, R.D., England, P., Rumble, D., 1999. Fluid Flow in Chondritic Parent Bodies: Deciphering the Compositions of Planetesimals. Science 286, 1331-1335. doi:10.1126/science.286.5443.1331

Yurimoto, H., Itoh, S., Zolensky, M., Kusakabe, M., Karen, A., Bodnar, R., 2014. Isotopic compositions of asteroidal liquid water trapped in fluid inclusions of chondrites. GEOCHEMICAL JOURNAL 48, 549-560. doi:10.2343/geochemj.2.0335

Yurimoto, H., Kuramoto, K., 2004. Molecular cloud origin for the oxygen isotope heterogeneity in the solar system. Science 305, 1763-1766. doi:10.1126/science.1100989

Zheng, Y.F., 1993. Calculation of oxygen isotope fractionation in anhydrous silicate minerals. Geochim. Cosmochim. Acta 57, 1079-1091. doi:10.1016/0016-7037(93)90042-u

Zhu, Z., Nelson, R.P., Dong, R., Espaillat, C., Hartmann, L., 2012. Dust filtration by planetinduced gap edges: Implications for transitional disks. Astrophys. J. 755, 6-18. doi:10.1088/0004-637X/755/1/6

Zolensky, M., Barrett, R., Browning, L., 1993. Mineralogy and composition of matrix and chondrule rims in carbonaceous chondrites. Geochim. Cosmochim. Acta 57, 3123-3148. doi:10.1016/0016-7037(93)90298-b

Zolensky, M.E., Bodnar, R.J., Yurimoto, H., Itoh, S., Fries, M., Steele, A., Chan, Q.H.S., Tsuchiyama, A., Kebukawa, Y., Ito, M., 2017. The search for and analysis of direct samples of early Solar System aqueous fluids. Philosophical Transactions of the Royal Society A: Mathematical, Physical and Engineering Sciences 375, 20150386. doi:10.1098/rsta.2015.0386

Zolensky, M.E., Mittlefehldt, D.W., Lipschutz, M.E., 1997. CM chondrites exhibit the complete petrologic range from type 2 to 1. Geochim. Cosmochim. Acta 61, 5099-5115. doi:10.1016/s0016-7037(97)00357-8

Zolotov, M.Y., Mironenko, M.V., Shock, E.L., 2006. Thermodynamic constraints on fayalite formation on parent bodies of chondrites. Meteoritics \& Planetary Science 41, 1775-1796. doi:10.1111/j.1945-5100.2006.tb00451.x 